\title{
Development, test and application of DrainFlow: a fully distributed integrated surface-subsurface flow model for drainage study
}

\author{
Ali Shokri, William Earl Bardsley \\ Faculty of Science and Engineering, Univ. of Waikato, Private Bag 3105, \\ Hamilton 3240, New Zealand
}

\begin{abstract}
Hydrological and hydrogeological investigation of drained land can be considered as a complex and integrated procedure. The scale of drainage studies may vary from a high-resolution small scale project through to a comprehensive catchment or regional scale investigation. This wide range of scales and integrated system behaviour poses a significant challenge for the development of a suitable drainage model. To meet these requirements, a fully distributed coupled surface-subsurface flow model named henceforth DrainFlow is developed and described here. DrainFlow includes both the Saint Venant equations for surface flow components (overland flow, open drain, tile drain) and the Richards equation for saturated/unsaturated zones.
\end{abstract}

To overcome the non-linearity problem created from switching between wet and dry boundaries, a smooth switching technique is introduced to buffer the model at tile drains and interface surface-subsurface flow boundaries. This gives a continuous transition between Dirichlet and Neumann boundary conditions. DrainFlow applied to some drainage study standard examples is found to be quite flexible in terms of changing all or part of the model dimensions as required by problem complexity, problem scale, and data availability. This flexibility gives DrainFlow the capacity to be modified to meet the specific requirements of varying scale and boundary conditions, as often encountered in drainage studies. Compared to traditional drainage models, DrainFlow has the advantage of estimating 
the land surface recharge directly from the partial differential form of Richards equation rather than through analytical or empirical infiltration approaches like the Green and Ampt equation.

Keywords: drainage, physically based, interaction, linked, surfacesubsurface, flow, integrated, coupled, groundwater, surface flow, subsurface flow, irrigation

\section{Introduction}

In an artificially drained zone, during a rain recharge event water infiltrates from the ground surface through the soil profile to the saturated zone, raising the water table. Water in the saturated zone then moves to tile drains and subsurface drainage networks. If the rainfall rate exceeds the infiltration capacity, because of either a change in rainfall or infiltration rate, ponding may occur at the ground surface as water accumulates at ground surface micro-topography. After filling surface depressions, further rainwater moves as surface overland flow or along small micro-channels. After rainfall cessation, infiltration will continue until the remnant surface water either drains away or evaporates.

Developing a comprehensive model for an artificially drained land area remains a challenge for hydrological and groundwater models. The reason is that modelling is made difficult because the subsurface drainage process as described above strongly connects to surface flow [1]. Furthermore, the modelled spatial scale may vary from high-resolution small scale investigations through to comprehensive catchment or regional-scale studies.

To date, many empirical and analytical expressions [2-24] and numerical solutions [25-38] have been developed to identify the relation between tile drain discharge and soil hydrodynamic properties, tile drain depth, and drain spacing. In addition, a number of special-purpose computer codes have been developed for estimating optimal drain spacing, including DRAINMOD [39], DRENAFEM [33] and MHYDAS-DRAIN [40]. However, both analytical and numerical drainage models rarely incorporate both the surface and subsurface flow with connection between overland flow and 
groundwater movement. In fact, neither subsurface nor surface flow models alone are capable of reflecting the complete surface-subsurface flow behaviour of a complex and integrated environmental system such as an artificially drained land surface.

Coupled surface-subsurface flow has been extensively investigated over the last decade in many hydrological and hydrogeological studies. The literature describes a range of environmental process applications including irrigation and drainage [41-48], solute transport and particletracking [49, 50], sediment transport [51, 52], flood control [53], residence time and hydrograph separation [54-59], land surface recharge [60-62], and runoff generation [57, 63-73].

In addition, some interaction surface and subsurface flow models have been developed. This includes, for example, ParFlow [74-76] PAWS [77], CATHY [78], HydroGeoSphere (HGS) [79, 80], InHM [71, 81], tRIBS + VEGGIE [82-84], and OpenGeoSys (OGS) [85-87]. In spite of the considerable effort in this field, none of the available codes are specialized to allow for the scale variation that is often encountered in drainage studies. This wide range of scales poses a significant challenge for the development of a suitable general drainage model.

As a contribution to the subject area, a fully distributed new coupled surface-subsurface model named hereafter as DrainFlow is presented here. DrainFlow includes several modules for surface flow: overland flow, open drain, tile/mole drains and surface water networks. Subsurface flow is incorporated via a saturated/unsaturated module. To develop the complete model, surface and subsurface flow modules are formulated separately and then each component connected to all the others. All modules interact to yield soil moisture water level in the subsurface domain, overland flow, and outflow in tile and open drains.

To overcome the non-linearity problem created from switching between dry and wet boundaries, a new technique is included in DrainFlow as a guard against this nonlinearity issue. The new technique provides smooth 
switching between wet and dry boundary conditions to buffer the model at tile drains and interface surface-subsurface flow boundaries.

The most useful feature of DrainFlow is that it has the capability to alter its dimensioning of surface and subsurface flow domains, depending on the complexity of the problem, scale, and the availability of data. Even though higher dimensions define a wider range of problems, in many cases useful solutions can be obtained via lower-dimension surface and subsurface flow models. Also, in contrast to traditional analytical and numerical drainage models, DrainFlow has the advantage of estimating land surface recharge directly from the partial differential Richards equation [88] rather than using analytical and empirical methods like Green and Ampt [89].

With reference to the structure of this chapter, sections 2 to 4 introduce the surface and subsurface flow modules, relevant equations, and the methodology applied to couple the equations and modules. DrainFlow was tested against five well-known integrated surface-subsurface flow problems and results are discussed in the section 5. In addition two applications of DrainFlow in some examples are described in Section 6.

\section{Model development}

\section{Overview}

In a tile drained catchment, the hydrological components such as tile/mole drains, open drains, rivers network, groundwater table, and soil moisture are hydrologically connected. To give best approximation to an environmental system, all model elements should reflect these distinctive but interacting hydrological elements. That is, the modules need to interact to properly mimic reality.

From this conception, application of DrainFlow requires initial separate formulation of the surface and subsurface flow modules, and then each module connects to the related components. Consequently, DrainFlow incorporates a wide range of modules including overland flow, tile/mole drain, open drain, river network, and subsurface flow. The general form of the DrainFlow conceptual model and components is shown in Fig 1. 


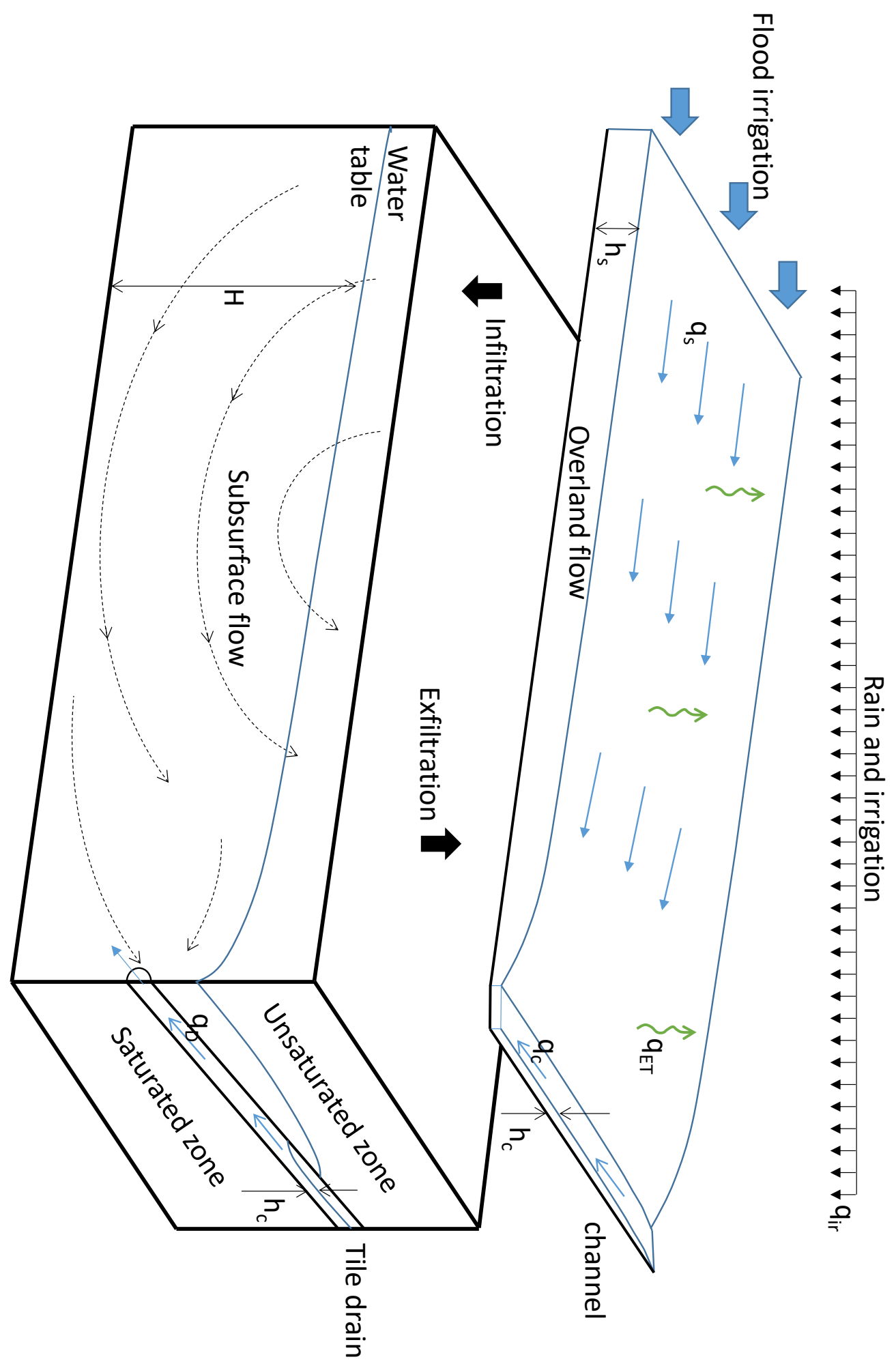

Fig 1. Schematic overview of the DrainFlow structure and components 


\section{DrainFlow Overland flow module (OL)}

Overland flow is defined by the governing equation which includes a mass conservation law and two momentum equations known as the SaintVenant (shallow water) equations:

$$
\left\{\begin{array}{l}
\frac{\partial H_{S}}{\partial t}+\frac{\partial\left(h_{s} u\right)}{\partial x}+\frac{\partial\left(h_{s} v\right)}{\partial y}=q_{e} \\
\frac{\partial\left(h_{s} u\right)}{\partial t}+\frac{\partial\left(h_{s} u^{2}\right)}{\partial x}+\frac{\partial\left(h_{s} u v\right)}{\partial y}+g h_{s}\left(\frac{\partial H_{s}}{\partial x}+S_{f x}\right)=0 \\
\frac{\partial\left(h_{s} v\right)}{\partial t}+\frac{\partial\left(h_{s} v^{2}\right)}{\partial y}+\frac{\partial(u v)}{\partial x}+g h_{s}\left(\frac{\partial H_{s}}{\partial y}+S_{f y}\right)=0
\end{array}\right.
$$

where $h_{s}$ is the water depth, $H_{s}=h_{s}+Z_{s}$ and $Z_{s}$ is ground surface elevation, $u$ and $v$ are the depth-averaged flow velocity in the $x$ and $y$ directions, $S_{f x}$ and $S_{f y}$ are friction slopes in $x$ and y directions, $g$ is the gravitational acceleration, qe represents source-sink terms per unit area:

$$
q_{e}=q_{i r}-q_{E T}-q_{21}
$$

where $q_{i r}$ is the time series of rainfall and/or irrigation per unit area, $q_{E T}$ is the time series of evapotranspiration per unit area, $q_{21}$ is the exchange flux between the subsurface flow and overland flow per unit area.

It is important to note that a number of approximations are made for derivation of the Saint Venant equations: constant fluid density, hydrostatic pressure distribution, zero surface shear stress with air, neglecting other source-sink terms in flow field, neglecting the momentum flux due to eddy viscosity, and neglecting external momentum-impulse. In addition, water depth $h_{\mathrm{s}}$ is required to be much smaller than wave length or the characteristic length of the water body. The Saint Venant equations are therefore only valid for situations of shallow water and gentle slopes [90].

Despite the simplifications involved, solving the Saint Venant equations in their comprehensive form remains a challenge. To overcome this difficulty the first three terms of momentum equations are assumed to be negligible. This is known as the "diffusive-wave" or "zero-inertia" assumption. If the friction slope is approximated by the Manning formula then $u$ and $v$ velocities can be expressed as [61]: 


$$
u=-\frac{1}{n_{\mathrm{x}}}\left(\frac{h_{s}}{1+S_{0 x}^{2}}\right)^{\frac{2}{3}} \frac{1}{\sqrt{\left|\frac{\partial H_{s}}{\partial x}\right|}} \frac{\partial H_{s}}{\partial x} ; \quad v=-\frac{1}{n_{\mathrm{y}}}\left(\frac{h_{s}}{1+S_{0 y}^{2}}\right)^{\frac{2}{3}} \frac{1}{\sqrt{\left|\frac{\partial H_{s}}{\partial y}\right|}} \frac{\partial H_{s}}{\partial y}
$$

where $S_{0 x}$ and $S_{0 y}$ are ground surface slope, and $n_{x}$ and $n_{y}$ are the Manning roughness coefficients in the $x$ and $y$ directions, respectively. The mass balance equation can now be rewritten by substituting Eq 3 into the first formula of Eq 1 as:

$$
\frac{\partial H_{S}}{\partial t}-\frac{\partial}{\partial x}\left(\frac{h s^{5 / 3}}{n_{x}\left(1+S_{0 x}^{2}\right)^{2 / 3}} \frac{1}{\sqrt{\left|\frac{\partial H_{s} \mid}{\partial x}\right|}} \frac{\partial H_{s}}{\partial x}\right)-\left(\frac{h s^{5 / 3}}{n_{y}\left(1+S_{0 y}^{2}\right)^{2 / 3}} \frac{1}{\sqrt{\left|\frac{\partial H_{s}}{\partial y}\right|}} \frac{\partial H_{S}}{\partial y}\right)=q e
$$

Eq 4 can be further simplified by replacing $\sqrt{\left|\partial H_{s} / \partial x\right|}$ and $\sqrt{\left|\partial H_{s} / \partial y\right|}$ by $\sqrt{\left|S_{0 x}\right|}$ and $\sqrt{\left|S_{0 y}\right|}$ respectively, known as linearized or semi diffusive wave approach, yielding:

$$
\frac{\partial H_{S}}{\partial t}-\frac{\partial}{\partial x}\left(\frac{h s^{5 / 3}}{n_{x}\left(1+S_{0 x}^{2}\right)^{2 / 3}} \frac{1}{\sqrt{\left|S_{0 x}\right|}} \frac{\partial H_{s}}{\partial x}\right)-\left(\frac{h s^{5 / 3}}{n_{y}\left(1+S_{0 y}^{2}\right)^{2 / 3}} \frac{1}{\sqrt{\left|S_{0 y}\right|}} \frac{\partial H_{S}}{\partial y}\right)=q e
$$

DrainFlow incorporates two types of boundary condition for the overland flow module, critical depth (Eq 6) and the zero depth gradient condition (Eq 7) [91].

$$
\begin{aligned}
& \frac{\partial H}{\partial x}=\sqrt{g h_{S}^{3}} \\
& \frac{\partial H}{\partial n}=\frac{h s^{5 / 3}}{n_{n}\left(1+S_{0 n}^{2}\right)^{2 / 3}} \frac{1}{\sqrt{\left|S_{0 \mathrm{n}}\right|}}
\end{aligned}
$$

where $n_{n}$ and $S_{0}$ are the Manning roughness coefficient and slope in the direction perpendicular to the boundary respectively.

\section{Tile drains (TD)}

The unsteady and non-uniform flow in tile drains is a form of spatiallyvaried flow [62], and in DrainFlow the free-surface flow in the tile drains is represented by a one-dimensional open circular channel:

$$
\left\{\begin{array}{l}
\frac{\partial A}{\partial t}+\frac{\partial\left(A V_{D}\right)}{\partial s}=q_{e D} \\
\frac{\partial\left(A V_{D}\right)}{\partial t}+\frac{\partial\left(A V_{D}^{2}\right)}{\partial s}+g A\left(\frac{\partial H_{S D}}{\partial s}+s_{f D}\right)=0
\end{array}\right.
$$


where $s$ is the flow direction in the tile drain, $V_{D}$ is the velocity magnitude in $s$ direction, $A$ is the cross section area perpendicular to $s$ direction, $q_{\mathrm{eD}}$ is represents the tile drain source-sink terms, $S_{f D}$ is the friction slope in the $s$ direction.

$H_{s D}$ is the total head:

$$
H_{S D}=h_{s D}+Z_{D}
$$

where $h_{S D}$ is water depth in tile drain, and $Z_{D}$ is the elevation of the tile drain base. Beside the other assumptions listed for Eq 1, the density and viscosity of the drained water from the tile drain is assumed as for fresh water.

Using the diffusive wave approach and the Manning formula for friction slope, drain velocity $\left(V_{D}\right)$ is expressed as:

$$
V_{D}=-\frac{1}{n_{D}}\left(\frac{R}{1+S_{0 D}^{2}}\right)^{\frac{2}{3}} \frac{1}{\sqrt{\left|\frac{\partial H_{S D} \mid}{\partial s}\right|}} \frac{\partial H_{S D}}{\partial s}
$$

where $n_{D}$ is the pipe drain Manning roughness coefficient, $S_{O D}$ is the pipe drainage slope in flow direction, and $R$ is hydraulic radius [61].

The geometrical elements of tile drains are defined as:

$$
\left\{\begin{array}{c}
A=(\theta-\sin \theta) \frac{r_{0}^{2}}{2} \\
R=\frac{A}{P}=\frac{(\theta-\sin \theta)}{\theta} \frac{r_{0}}{2} \\
T=\frac{2 r_{0} \sin \theta}{2} \\
\theta=2 \cos ^{-1}\left(1-\frac{2 y}{d}\right)
\end{array}\right.
$$

where $P$ is the wetted perimeter, $T$ is top width of the free surface and $\theta$ is the tile drain cross section central angle in radians [63]. Geometrical elements of a cross section of a tile drain are shown in Fig 2. 


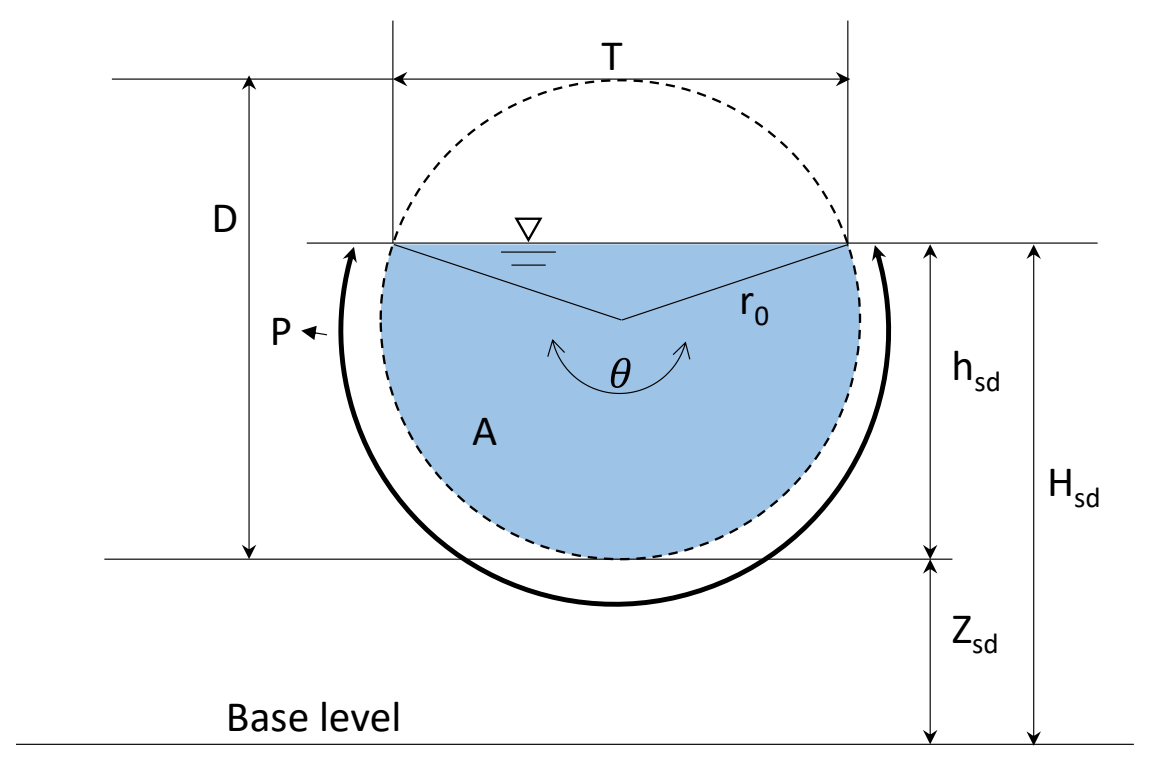

Fig 2. Geometrical cross section elements of a tile drain

Combining Eq 10 and the Saint-Venant equation, the governing equation of fluid flow in a tile drain is:

$$
T \frac{\partial H_{S D}}{\partial t}-\frac{\partial}{\partial s}\left(\frac{A R^{\frac{2}{3}}}{n_{d}\left(1+S_{0 D}^{2}\right)^{\frac{2}{3}}} \frac{1}{\sqrt{\left|\frac{\partial H_{S D}}{\partial s}\right|}} \frac{\partial H_{S D}}{\partial s}\right)=q_{e D}
$$

When the tile drain is completely full, any extra water flow from the further upstream tiles may cause the inside pressure of the tile drain to be more than the outside pressure. As a result, the seepage direction would change and the tile drain would then serve as a source of water for groundwater. DrainFlow always checks the computed pressure of tile drains to detect the discharge/recharge sources in the model.

\section{Open drains, channels and river networks (ODCR)}

The overland flow module is able to predict the surface flow and depth in the open drains, channels and rives. However, a high density model mesh is required in the open drain locations. To accelerate the DrainFlow simulation procedure, it is assumed that flow in the open drains is one dimensional, therefore to simulate flow in open drains the 2-dimensional Saint Venant equations is simplified as:

$$
\frac{\partial H_{s c}}{\partial t}-\frac{\partial}{\partial c}\left(\frac{h s c^{\frac{5}{3}}}{n_{c}\left(1+S_{0 c}^{2}\right)^{\frac{2}{3}}} \frac{1}{\sqrt{\left|S_{0 c}\right|}} \frac{\partial H_{s c}}{\partial c}\right)=q_{e c}
$$


where $c$ is the flow direction in open drain, $h_{s c}$ is the water depth in channel, $n_{c}$ and $S_{0 c}$ are the channel Manning roughness coefficient and slope in the $c$ direction, $q_{e c}$ is the sink/source term, and $H_{s c}$ is the channel total head:

$$
H_{s c}=h_{s c}+Z_{c}
$$

where $Z_{c}$ is the channel base elevation.

\section{Subsurface flow module (SSM)}

In the DrainFlow code, saturated and unsaturated flow in a porous medium utilises Richards equation as the governing equation:

$$
\nabla .\left(K_{r} K_{s} \nabla H\right)=S_{s} S_{w} \frac{\partial h_{p}}{\partial t}+\varphi \frac{\partial S_{w}}{\partial t}+q e_{s}
$$

where $K_{s}$ is the saturated hydraulic conductivity tensor, $S_{s}$ is the specific storage coefficient, $S_{w}$ is the water saturation, $h_{p}=H-Z$ is the pressure head, $H$ is the total head, $Z$ is the elevation above an arbitrary datum, $\varphi$ is the porosity, $K_{r}$ is the relative permeability, and $q e_{s}$ represent subsurface flow source-sink terms per unit area.

In order to solve the Richards equation the relationships between $S_{w}-h_{p}$ and $K_{r}-S_{w}$ are required. In the DrainFlow code an analytical expression between the $S_{w}-h_{p}$ and $K_{r}-S_{w}$ terms is implemented following VanGenuchten [92]:

$$
\begin{aligned}
& S_{e}= \begin{cases}\left(1+\left|\alpha h_{p}\right|^{n_{V G}}\right)^{-m_{\text {VG }}} & \text { if } h_{p}<0 \\
1 & \text { if } h_{p} \geq 0\end{cases} \\
& K_{r}=S_{e}^{\text {IVG }^{\prime}}\left(1-\left(1-S_{e} e^{1 / m_{\text {VG }}}\right)^{m_{\text {VG }}}\right)^{2}
\end{aligned}
$$

where $S_{e}$ is the effective saturation, $I_{V G}$ is a pore connectivity parameter (usually assume to be 0.5 ), $\alpha$ and $n_{V G}>1$ are the two Van Genuchten fitting curve parameters and $m_{V G}=1-1 / n_{V G}$. 


\section{Coupling methods}

For coupling the surface and subsurface flow modules, the overland flow module is a boundary condition for the subsurface flow domain. Similarly, open drains are a boundary condition for the overland flow domain. The tile drains, however, are considered as an internal boundary condition for the subsurface flow module, which allows the infiltration rate to be calculated directly from the Richards equation for the tile drain module.

Fig 3 shows all potential connections between the modules in DrainFlow.

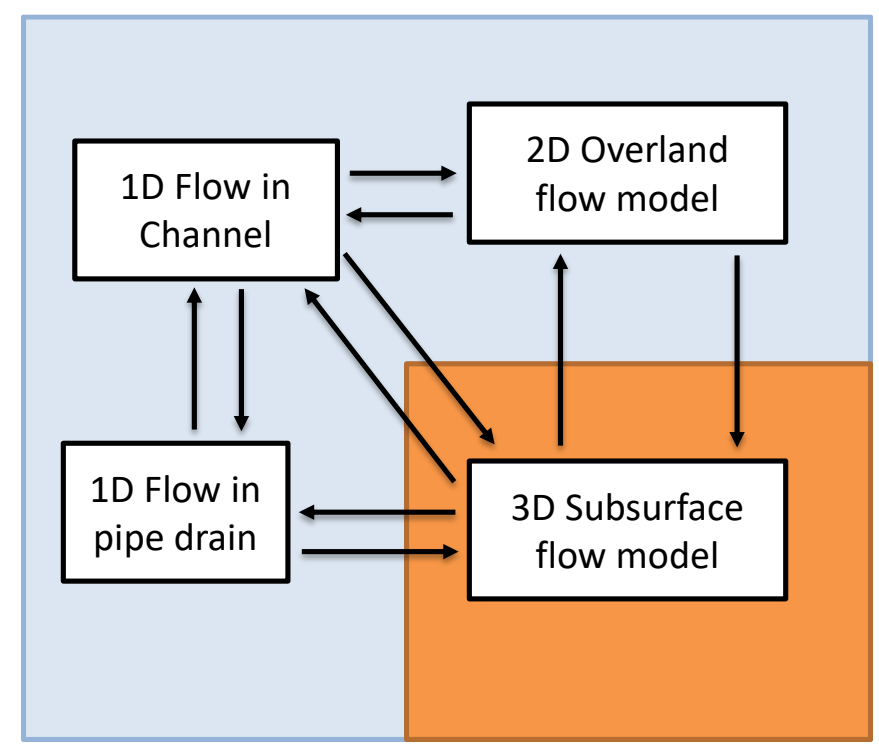

Fig. 3. DrainFlow modules and potential connections

\section{Subsurface and overland flow connection}

At the start of each time step, surface flow depth $\left(h_{s}\right)$, infiltration rate $(I)$ and effective rainfall rate $\left(q_{I R}\right)$ for all surface-subsurface flow interface boundaries are calculated, respectively, by the overland flow module, Eqs 18 and 19.

$$
\begin{aligned}
& I=K_{s} K_{r} \nabla H \\
& q_{\mathbb{R}}=q_{i r}-q_{E T}
\end{aligned}
$$

The calculated values are then used as decision making parameters to select either Neumann or Dirichlet boundary conditions for the interface boundaries between overland flow and subsurface flow domain. 
The current infiltration rate of the model is compared with effective rainfall. If the infiltration rate is larger than the effective rainfall $\left(I>q_{I R}\right)$ or runoff does not show up on the overland flow $\left(h_{s} \leq 0\right)$, then all the effective rainfall is passed to the subsurface model. Consequently, in the overland flow module the exchange flux between subsurface flow and overland flow $\left(q_{21}\right)$ is set as the effective rainfall, while in the subsurface flow module the interface boundary condition is set as a Neumann boundary condition with qIR specified flux.

DrainFlow keeps these conditions until either the infiltration rate becomes smaller than effective rain $\left(I \leq q_{I R}\right)$ or runoff flows off as overland flow $\left(h_{s}>0\right)$. Then, the excess rainfall to the infiltration flows as runoff on the overland flow domain. In this situation, the interface boundaries in the subsurface flow module switches from the specified flux (Neumann) to a constant head (Drichlet) boundary condition. The constant head boundary would be provided by the overland flow module $\left(H_{s}\right)$ in each time step. Consequently, in the overland flow module the exchange flux between subsurface flow and overland flow $\left(q_{21}\right)$ is set as the infiltration rate $(I)$.

To provide an automatic switching mechanism between Neumann and Drichlet boundary conditions a mixed boundary condition is introduced to the DrainFlow code:

$$
\left\{\begin{array}{l}
K_{r} K_{s} \nabla H=N_{o}+R_{b}\left(H_{s}-H\right) \\
R_{b}=K_{s}^{\prime} / M
\end{array}\right.
$$

where $H_{s}$ is the surface water total head, $H$ is the groundwater total head, $R_{\mathrm{b}}$ is the conductance of the interface boundary material, $K_{\mathrm{s}}$ and $M$ are respectively the hydraulic conductivity and the thickness of a thin layer next to the interface boundary. Eq 20 represents a Neumann boundary condition when $R_{\mathrm{b}}=0$, and a Dirichlet boundary condition when $R_{\mathrm{b}}$ is a large number and $N_{0}=0$ [58].

By using a Heaviside function $(H v(x))$,

$$
H v_{(x)}=\left\{\begin{array}{r}
-1, x<0 \\
1, x \geq 0
\end{array}\right.
$$


where $\mathrm{x}$ is the Heaviside function variable, the infiltration rate exchange between the overland flow and groundwater can be defined by:

$$
I_{O L \leftrightarrow S S M}=\left[H v\left(-h_{p}\right) H v\left(-h_{s}\right)\right] q_{\mathbb{R}}+\left[H v\left(-h_{p}\right)+H v\left(-h_{s}\right)\right] R_{b}\left(H_{s}-H\right)
$$

where $I_{O L \leftrightarrow S S M}$ is infiltration exchange between the overland flow and subsurface flow.

\section{Tile drain and subsurface module connections}

A seepage-face boundary condition is implemented for tile drains in the subsurface flow module. Once water flows in a tile drain or the pressure head at the drain boundary calculated by the subsurface model becomes larger than zero, the seepage-face boundary switches from a zero-flux to a constant head boundary condition.

By using a Heaviside function the infiltration rate exchange between tile drain and groundwater can be expressed as:

$$
I_{D M \leftrightarrow S S M}=\left(H v_{(h p)}+H v_{(h s d)}\right) R D_{b}\left(H_{s d}-H\right)
$$

where $I_{D M \leftrightarrow S S M}$ is the infiltration rate exchange between tile drain and subsurface flow and $R D_{b}$ is the entrance seepage conductance due to minor head loss at tile drains entrance.

$H_{S D}$ is the total head in the tile drain:

$$
H_{S D}=Z_{\text {out }}+S_{0 D} \times l_{S D}+h_{S D}
$$

where $Z_{\text {out }}$ is the tile drain outlet elevation, $S_{O D}$ is the pipe drainage slope in flow direction, and $I_{s D}$ is distance from the tile drain outlet .

\section{Open drain connections to overland flow and subsurface flow module}

To connect the overland flow and the open drain modules, at the start of each time step, the exchange flux rate between overland flow and open drain $\left(q_{o c}\right)$ is calculated by the overland flow module. Then $q_{o c}$ adds to the sink/source terms of open drain equation (Eq 13). 
In addition, to connect the subsurface flow and open drain modules, the exchange infiltration rate between open drain and subsurface flow ( $\left.I_{O D \leftrightarrow S S M}\right)$ is calculated as:

$$
I_{O D \leftrightarrow S S M}=[H v(-h p) H v(-h s c)] b c \times q_{\mathbb{R}}+[H v(-h p)+H v(-h s c)] R_{b c}\left(H_{c}-H\right)
$$

where $b c$ is the open drain width, $R b_{c}$ is the conductance of open drain materials.

$I_{O D \leftrightarrow S S M}$ also adds to the sink/source terms of the channel equation. Therefore, by adding $q_{o c}$ and $I_{O D \leftrightarrow S S M}$ to the sink/source terms of the channel equation, $q_{e c}$ is expressed as:

$$
q_{e c}=q_{o c}+l_{O D \leftrightarrow S S M}+q_{i r}-q_{E T}
$$

where $q_{o c}$ is the surface runoff as calculated directly by the overland flow module, and $I_{O \leftrightarrow S S M}$ is the exchange infiltration rate between open drain and subsurface flow.

\section{Tile drain and open drain (ODCR) connections}

Tile drains outflows often collect at an open drain known as the main drain. Flow in the main drains is simulated by the open drain module. To link the tile drains to a main drain (open drain), the computed tile drain outflow at the locations of each tile drains outlet are considered as an internal boundary condition for the main drain. Moreover, several tile drains as internal boundaries could be added to the main drain.

Alternatively, in some circumstances the main drain also could have effective impact on tile drains operation. For example, when water level in the main drain increases to an elevation higher than tile drain outlet level, then the main drain acts as a barrier for the tile drain flow and water push back into the tile drains.

For simulating this impact in the DrainFlow code, once the total head in the main drain increases to an elevation higher than the tile drain outlet level, the exceeded head over the tile drain outlet level automatically adds to the elevation of the tile drain base. 


$$
Z_{D o}=Z_{D b}+H_{m T}
$$

where $Z_{D o}$ is the calculated tile drain base elevation at the outlet, $Z_{D b}$ is the actual elevation of the tile drain at the outlet and $H_{m T}$ is the exceed head over the tile drain base at the out let. The amount of $H_{m T}$ is calculated by the main drain module for each time step.

\section{Smoothed Heaviside function}

Switching between Neumann and Dirichlet boundary condition can cause nonlinearity problems. In DrainFlow code to avoid these issues the Heaviside function $H v(x)$ is replaced by smoothed Heaviside functions. Many smoothed Heaviside functions are recommended in the literature, one utilised here being the logistic function:

$$
\operatorname{Logistic}(x, \text { err })=\left(1+\exp \left(-\frac{x}{e r r}\right)\right)^{-1}
$$

where err is the specified smoothing factor.

Another example is the flc2hs $(x$, err) function of COMSOL [93] which is a smoothed Heaviside function with continuous second derivative without overshoot. The values of the $f l c 2 h s(x$, err) is defined as 0 for $x<$-err, 1 for $x>e r r$ and a sixth-degree polynomial fitting curve for the gap between -err and err $(-\mathrm{err}<\mathrm{x}<\mathrm{err})$.

Fig 4 shows an approximation of logistic and flc2hs( $x$, err) smoothed Heaviside functions using a range of smoothing factors (err). Decision about the optimum err values is a trade-off between model accuracy and convergence time. Depending on the model condition, err values should be decided separately for each simulation. 


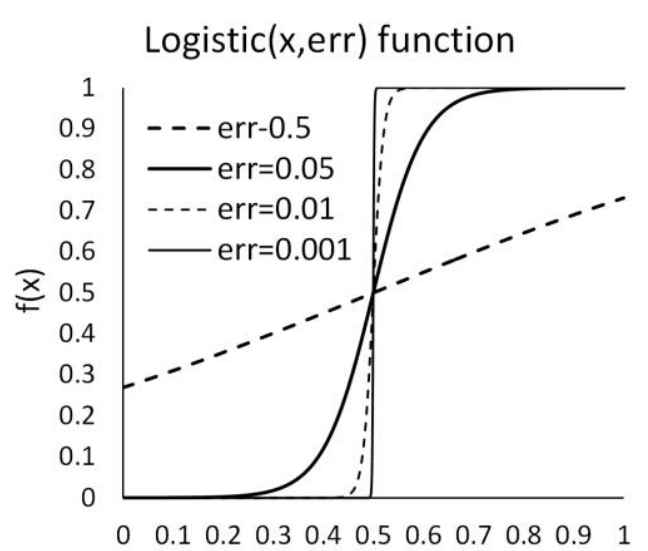

$\mathrm{X}$
Comsol flc2hs(x,err) function

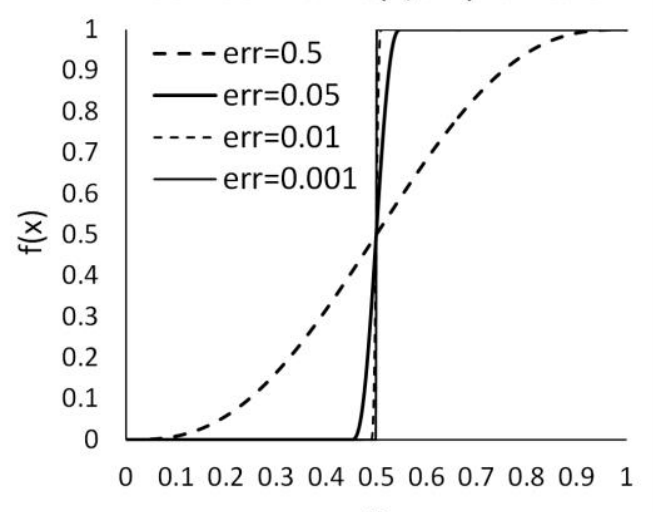

$\mathrm{X}$

Fig 4. A comparison between smoothed Heaviside functions with different smoothed parameters: Logistic and Comsol flc2hs functions. These smoothed functions are used as replacements for the Heaviside function in DrainFlow.

\section{Benchmark tests}

To check the model capability on integrated surface-subsurface flow problems, this section gives some comparisons between DrainFlow and seven known coupled surface-subsurface flow codes: CATHY [78], HydroGeoSphere (HGS) [79, 80], OpenGeoSys (OGS) [85-87], ParFlow [74-76], PAWS [77], PIHM [71, 81], and tRIBS + VEGGIE [82-84].

All codes apply the Richards equation for subsurface flow, coupled with some form of the Saint - Venant equations for estimation of surface flow discharge. However, they use a different formulation of partial differential governing equations, interface boundary conditions and numerical methods.

The comparisons utilise five frequently published integrated surfacesubsurface flow problems: infiltration excess (IE), saturation excess (SE), slab (Sb) and return flow (RF) benchmarks. These problems, organized in order of increasing complexity, are given by Maxwell et al [94]. The benchmarks have minimal complexity in domain geometry, topography, hydraulic hydrological properties and atmospheric forcing.

The benchmarks contain a simple tilted V-catchment or hill-slope for surface flow domain and a sloped layer of soil as subsurface flow domain. 
All simulations open with a rainfall event and follow by an evapotranspiration period with no further rainfall. The benchmarks all use the same values for Van-Genuchten parameters ( $\alpha$ and $n_{V G}$ ), residual and saturated water content ( $S_{\text {res }}$ and $S_{\text {sat }}$ ), porosity $(\varphi)$ and specific storage $\left(S_{s}\right)$. However, different values are implemented for saturated hydraulic conductivity $\left(K_{S}\right)$, initial water table $(I w t)$, ground surface slope $\left(S_{x}\right)$ in each problem. A conceptual model with a list of utilised parameters for the five benchmarks is illustrated in Fig 5 . 


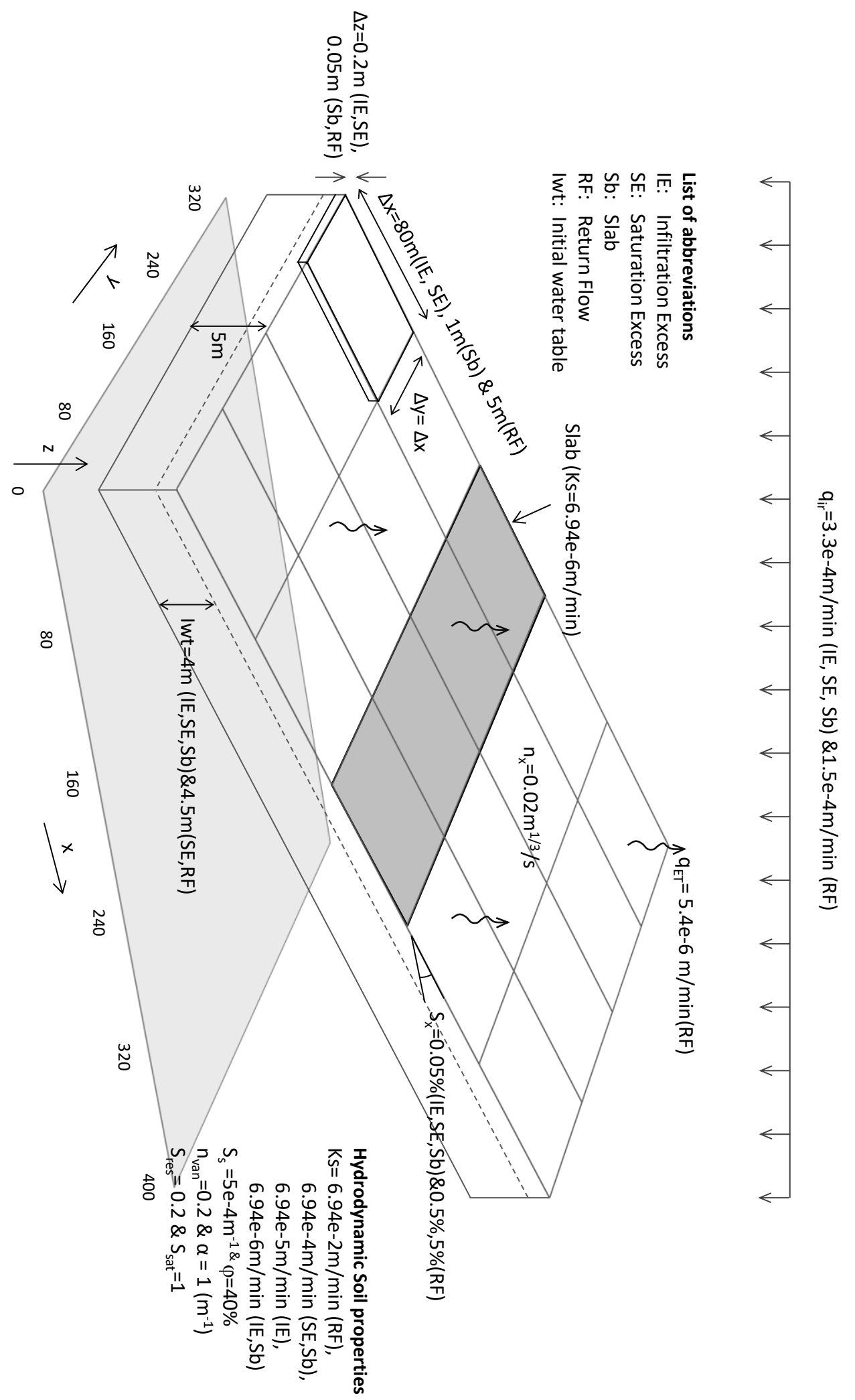

Fig 5. Conceptual model and list of parameters used in infiltration excess (IE), saturation excess (SE), slab (Sb) and return flow (RF) benchmarks. 


\section{Infiltration excess runoff scenarios}

For the first test the DrainFlow code simulates infiltration excess overland flow, also known as Hortonian runoff. This exercise includes two scenarios: (i) saturated hydraulic conductivity at $6.94 \times 10^{-6} \mathrm{~m} / \mathrm{s}$ and (ii) saturated hydraulic conductivity at $6.94 \times 10^{-5} \mathrm{~m} / \mathrm{s}$. The hydraulic conductivities for both scenarios were selected to be higher than the rainfall rate, generating a Hortonian runoff condition.

Both simulations start with a constant rainfall rate of $3.3 \times 10^{-4} \mathrm{~m} / \mathrm{min}$ for 200 min and continued by a 100 min of drainage period.

Evapotranspiration was neglected for both scenarios. Therefore, the rainfall is equal to effective rainfall for this example.

Predicted discharge at the outlet by DrainFlow and the other integrated hydrologic models (called hereafter as "IHMs") given by Maxwell et al [94] are shown in Fig 6.a. The simulated hydrographs show that in both scenarios runoff occur shortly after the beginning of rainfall. Apart from an earlier arrival at the steady state condition in the first scenario, DrainFlow has a reasonably good agreement with the other IHMs.

In addition, a sensitivity analysis was carried out to investigate the effect of the $M$ parameter on the discharge peak in the second scenario. DrainFlow was run for a wide range of $M$ from $0.1,0.01$ to $1 \mathrm{e}-7 \mathrm{~m}$ and the discharge peaks calculated as $7.18,7.17$ and $7.12 \mathrm{~m}^{3} / \mathrm{min}$ respectively. Even with a large change in the $M$ magnitude, DrainFlow does not show sensitivity in predicting the discharge peak. However, simulation time is increased by implementing smaller values for $M$. 

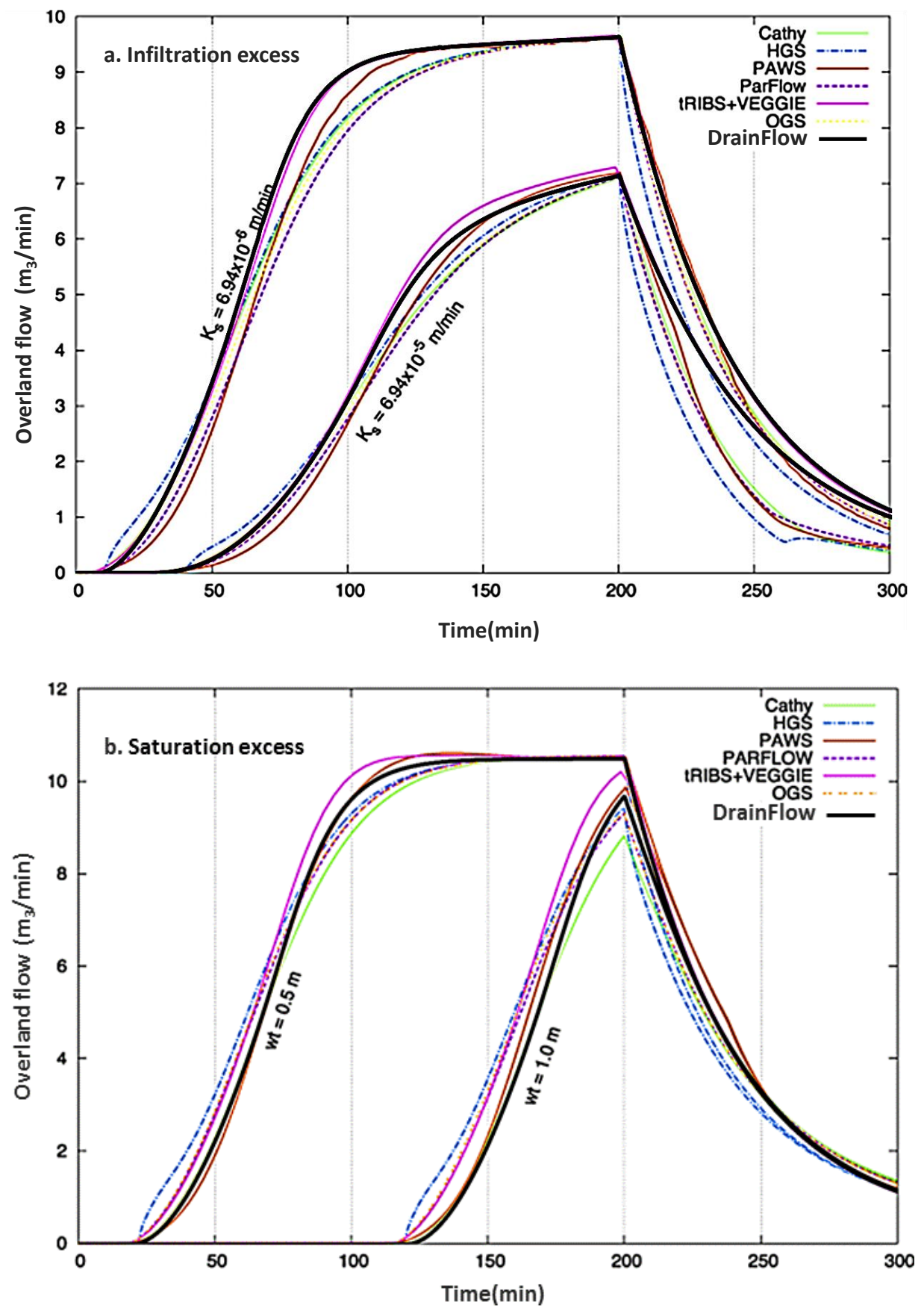

Fig 6. Comparisons between DrainFlow and the other IHMs (given by Maxwell et al [94]) for predicting overland-flow hydrographs at the hillslope toe; (a). infiltration excess runoff; (b). saturation excess runoff benchmarks

\section{Saturation excess runoff scenarios}

The saturation excess runoff benchmark is very similar to the infiltration excess cases but the hydraulic conductivity is smaller than the rainfall rate $\left(q_{I R} / K_{s}=0.467\right)$. The saturation excess runoff exercise also runs for two 
scenarios the initial water table below the ground surface level is $1 \mathrm{~m}$ and for the second scenario is $0.5 \mathrm{~m}$. The overland flow hydrographs at the hillslope outlet by DrainFlow and the other models are shown in Fig 6.b.

At the start of both scenarios the entire amount of rainfall leads to raising the groundwater table. This process continues until the groundwater table reaches the ground surface. From this point (also known as ponding time) a portion of rainfall flows off as runoff. The model estimated the ponding times to occur at around 22 and 121 minutes for the first and second scenarios respectively. A comparison between the hydrographs of the various models in Fig 6.b indicates the DrainFlow hydrographs and ponding time predictions are similar to the other IHMs.

\section{Slab case}

The slab benchmark case was introduced by Kollet and Maxwell [75] to challenge coupled surface-subsurface flow codes when the soil is not homogeneous. The slab benchmark domain is very similar to saturation excess runoff scenario, but a thin slab with low hydraulic conductivity is located at the top centre of the subsurface flow domain. The dimension of the slab is $100 \mathrm{~m}$ in length, $5 \mathrm{~cm}$ in thickness, and $320 \mathrm{~m}$ in width. The slab saturated hydraulic conductivity is $6.94 \times 10^{-6} \mathrm{~m} / \mathrm{s}$, which is 100 times less than the rest of subsurface flow domain.

DrainFlow model runs for the slab benchmark and the calculated hydrograph at the outlet of the hill-slope are compared with the other surface-subsurface model in Fig 7. 


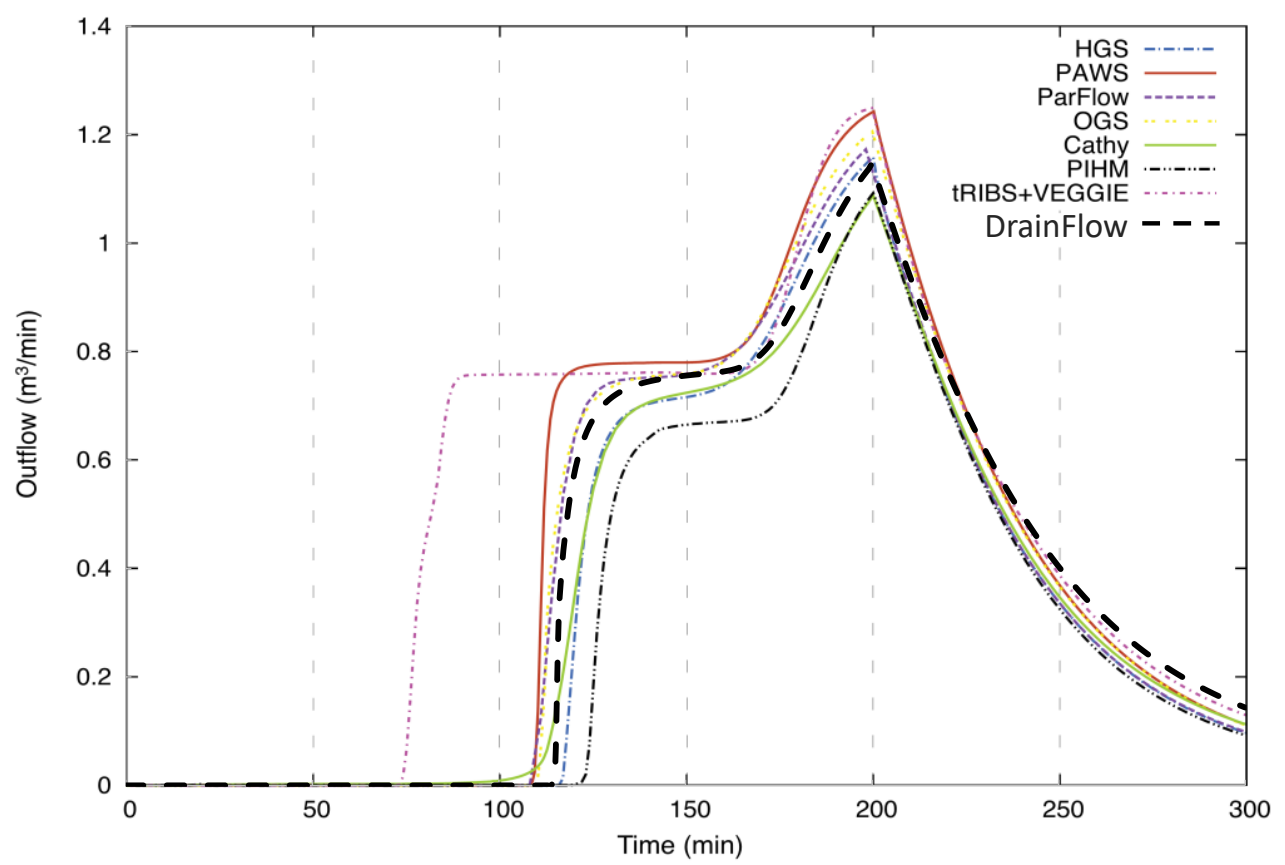

Fig 7. Comparison between DrainFlow and the other IHMs overland-flow hydrographs (Maxwell et al [94]) at the hill-slope outlet

As a response to the soil heterogeneity specified in the benchmark, DrainFlow predicts step-like hydrographs at the hill slope outlet. The first jump in the hydrograph results from the runoff generated by the slab component. Fig 7 shows the DrainFlow overland flow hydrograph increases rapidly to $0.75 \mathrm{~m}^{3} / \mathrm{min}$ at about 115 minutes and discharge almost remains stable for a short period of time. However, the hydrograph peaks again at $1.14 \mathrm{~m}^{3} / \mathrm{min}$ at around 160 minutes due to late runoff generated by the part upper than the slab. Fig 7 shows the maximum discharge calculated by DrainFlow is very similar to the results of Parflow and OGS for the slab benchmark.

\section{Return flow}

The hill-slope in the return flow benchmark is much steeper than the other benchmarks. The DrainFlow code simulated two scenarios, with $S_{x}$ set at $0.5 \%$ and $5 \%$ respectively. The model was run for continuous rainfall at $1.5 \times 10^{-4} \mathrm{~m} / \mathrm{min}$ for 200 minutes followed by an evapotranspiration period of 200 minutes with an evapotranspiration rate of $5.4 \times 10^{-6} \mathrm{~m} /$ minute. 
Fig 8 illustrates the intersection point between the water table and ground surface versus time, derived from DrainFlow and the other models given by Maxwell et al [94].
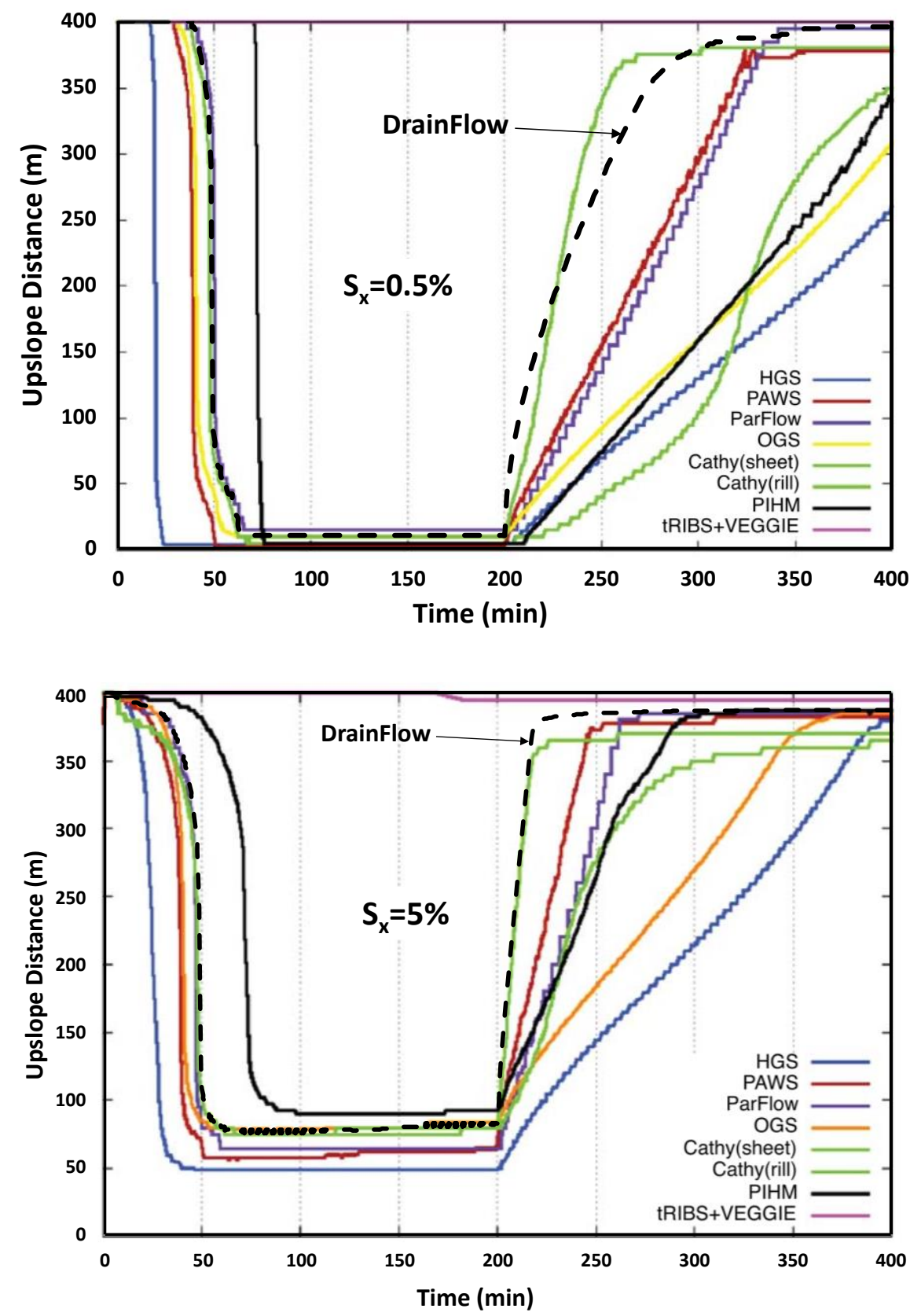

Fig 8. The intersection point between the water table and ground surface as a function of time for $\mathrm{Sx}=0.5$ and $5 \%$ slope, as obtained from DrainFlow and other models.

Although there are some similarities, the coupled surface-subsurface flow models show a range of predictions. Results of DrainFlow for the period of rainfall are very similar to the ParFlow and Cathy codes and for the 
evaporation period are similar to the Cathy code prediction in both scenarios.

\section{V-Catchment}

The V-catchment benchmark comprises two 1000 x 800m tilt planes, joined by a $1000 \times 20 \mathrm{~m}$ channel in the middle (Fig 9). The ground surface slopes are $2 \%$ and $5 \%$, respectively, parallel and perpendicular to the channel direction. The benchmark starts with a 90min uniform rainfall at the $1.810^{-5} \mathrm{~m} / \mathrm{min}$ rate and follows by $90 \mathrm{~min}$ recession period. Despite the fact that the $\mathrm{V}$-catchment benchmark does not contain a subsurface flow domain, this test could challenge the methodology used to connect the $2 \mathrm{D}$ overland flow and 1D open drain modules. Fig 9 compares the channel hydrograph at the outlet predicted by DrainFlow with the other interaction surface-subsurface flow models of Maxwell et al [94]. 
a

$\mathrm{q}_{\mathrm{ir}}=1.8 \mathrm{e}-4(\mathrm{~m} / \mathrm{min})$

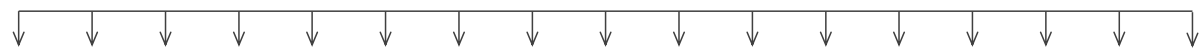

Manning's roughness coefficient

Plans: $\quad n_{x}=n_{y}=0.015 \mathrm{~s} / \mathrm{m}^{-1 / 3}$

Channel: $n_{c}=0.015 \mathrm{~s} / \mathrm{m}^{-1 / 3}$
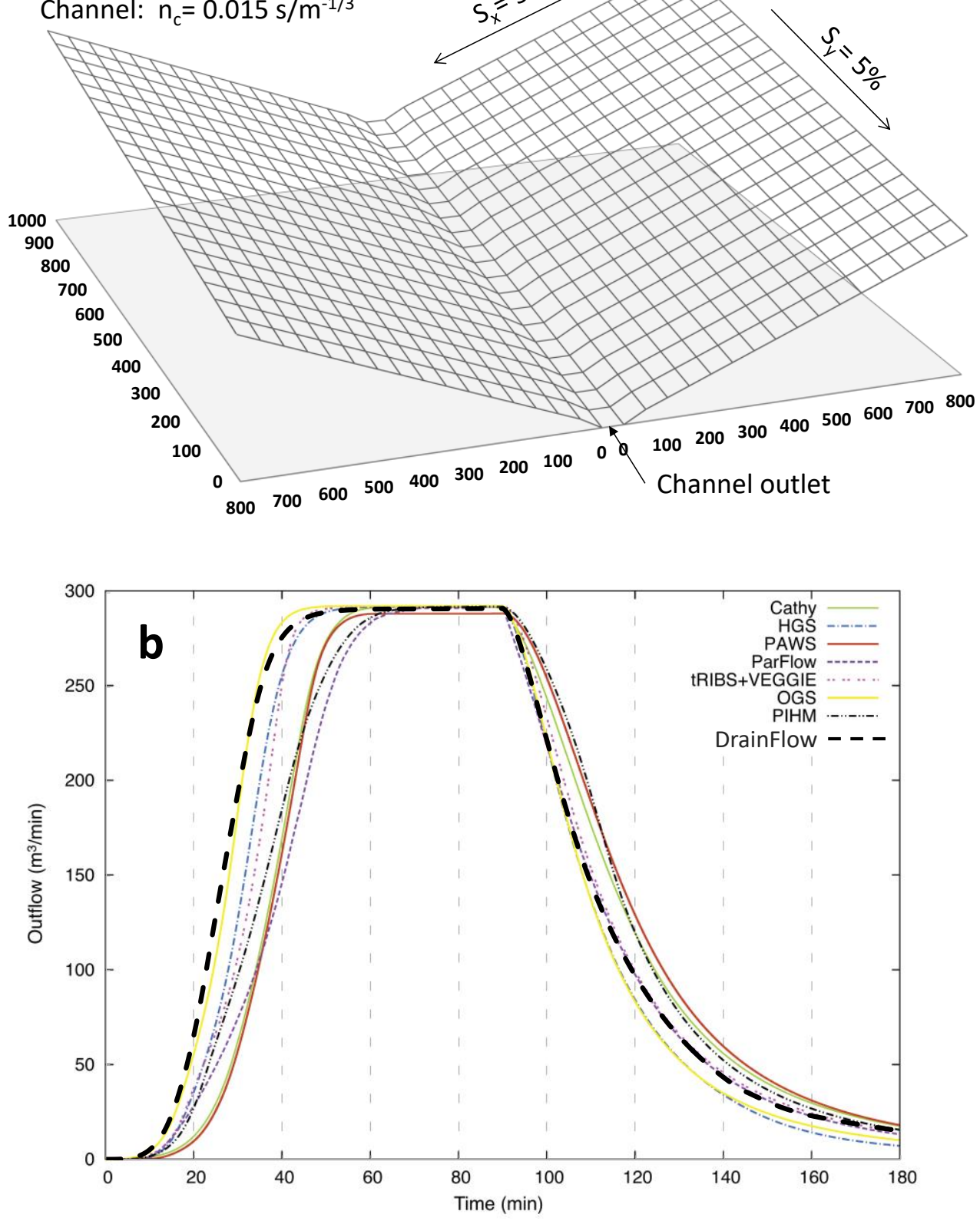

Fig 9. V-catchment benchmark: (a). conceptual model, (b). channel outflow hydrographs at the channel outlet predicted by DrainFlow and the other IHMs by Maxwell et al [94]

The DrainFlow hydrograph is similar to the OGS code prediction in the rising limb and is close to the Parflow model in the falling limb. The maximum discharge calculated by DrainFlow is $291.71 \mathrm{~m}^{3} / \mathrm{min}$ and it is accrued at around 83 minutes. 


\section{Application of DrainFlow for tile drainage examples}

DrainFlow was run for two hypothetical tile drainage examples. The first example includes a high-resolution and small-scale study containing a combination of different modules. The second example is designed to challenge the code in upscaling issues. For the second example the DrainFlow models an area 10 times larger than example 1 and contains up to 80 tile drains and two open drains.

\section{Example 1}

For the first example DrainFlow is set up for one tile drain which includes a 2D overland-flow, a 3D saturated-unsaturated flow, an open drain, and a tile drain module. The tile drain length is $100 \mathrm{~m}$ with a $10 \mathrm{~cm}$ radius, located at depth $2 \mathrm{~m}$ below the ground surface. The subsurface flow domain comprised a homogenous and isotropic soil with a gentle 1dimensional slope a right angles to the tile drain direction. The length, width and height of the soil layer are 100, 100 and $5 \mathrm{~m}$ respectively. Fig10 shows the conceptual model and utilised parameter values. 


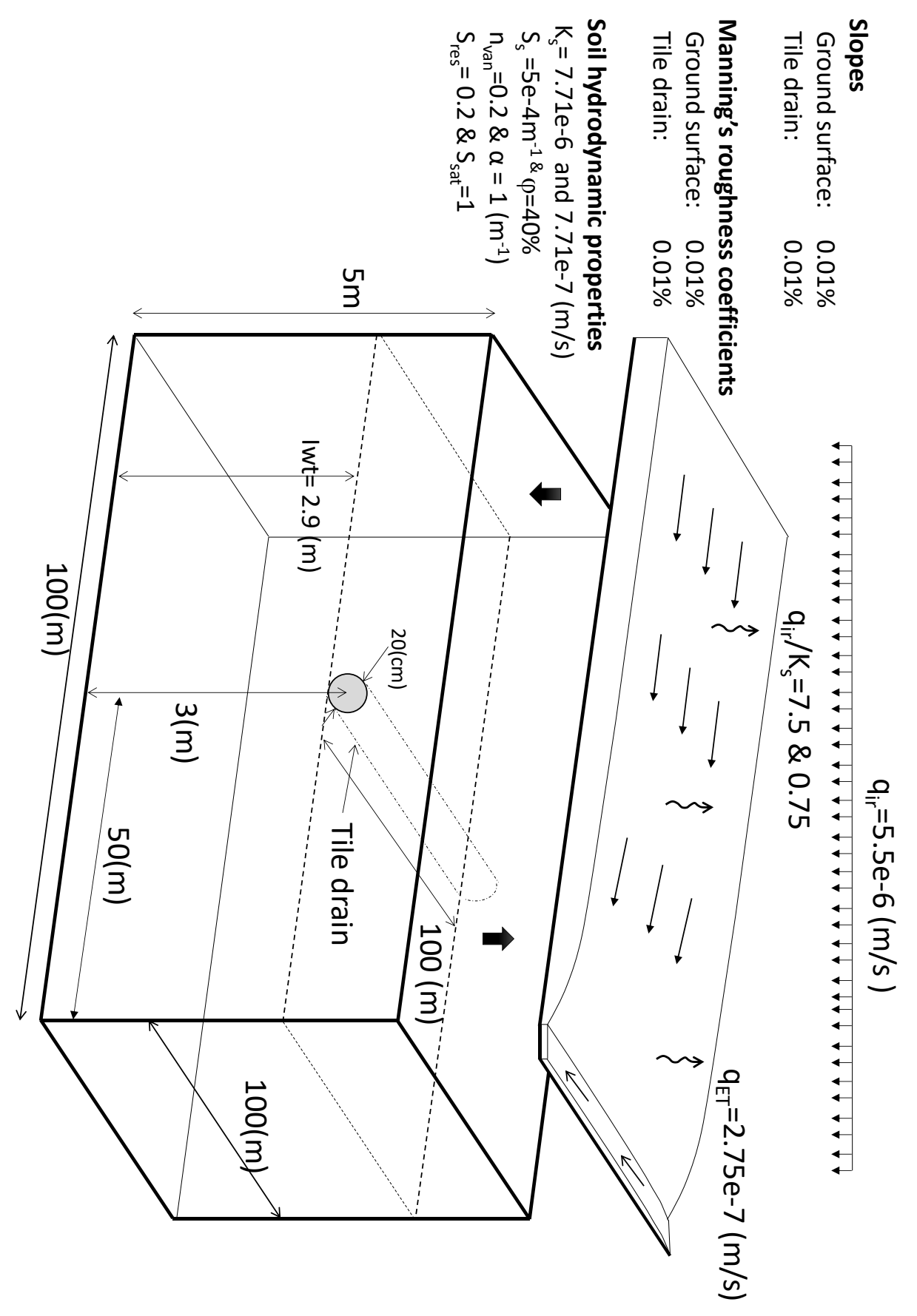

Fig 10. Example 1: untilised conceptual model of overland-flow, subsurface flow, tile drain, open drain module, and parameter values.

The model was run for two scenarios to simulate complete infiltration and saturation excess runoff conditions. The hydraulic conductivity values were set as smaller and larger than the effective rainfall rate for the infiltration and saturation excess runoff scenarios respectively.

The rainfall was fixed at a uniform rate of $5.5 \times 10^{-6} \mathrm{~m} / \mathrm{s}$ for a two-day period, followed by 8 days of evapotranspiration at a constant $2.75 \times 10$ 
${ }^{7} \mathrm{~m} / \mathrm{s}$. Hydraulic conductivity values were set at $7.71 \times 10^{-7}$ and $7.71 \times 10^{-6} \mathrm{~m} / \mathrm{s}$ for the infiltration and saturation excess conditions, respectively. The initial water table was located at the base of the tile drain at $2.1 \mathrm{~m}$ depth below the ground surface.

The simulated hydrographs at the outlets of the open drain and the tile drain are shown in Fig 11 for the infiltration and saturation excess scenarios.
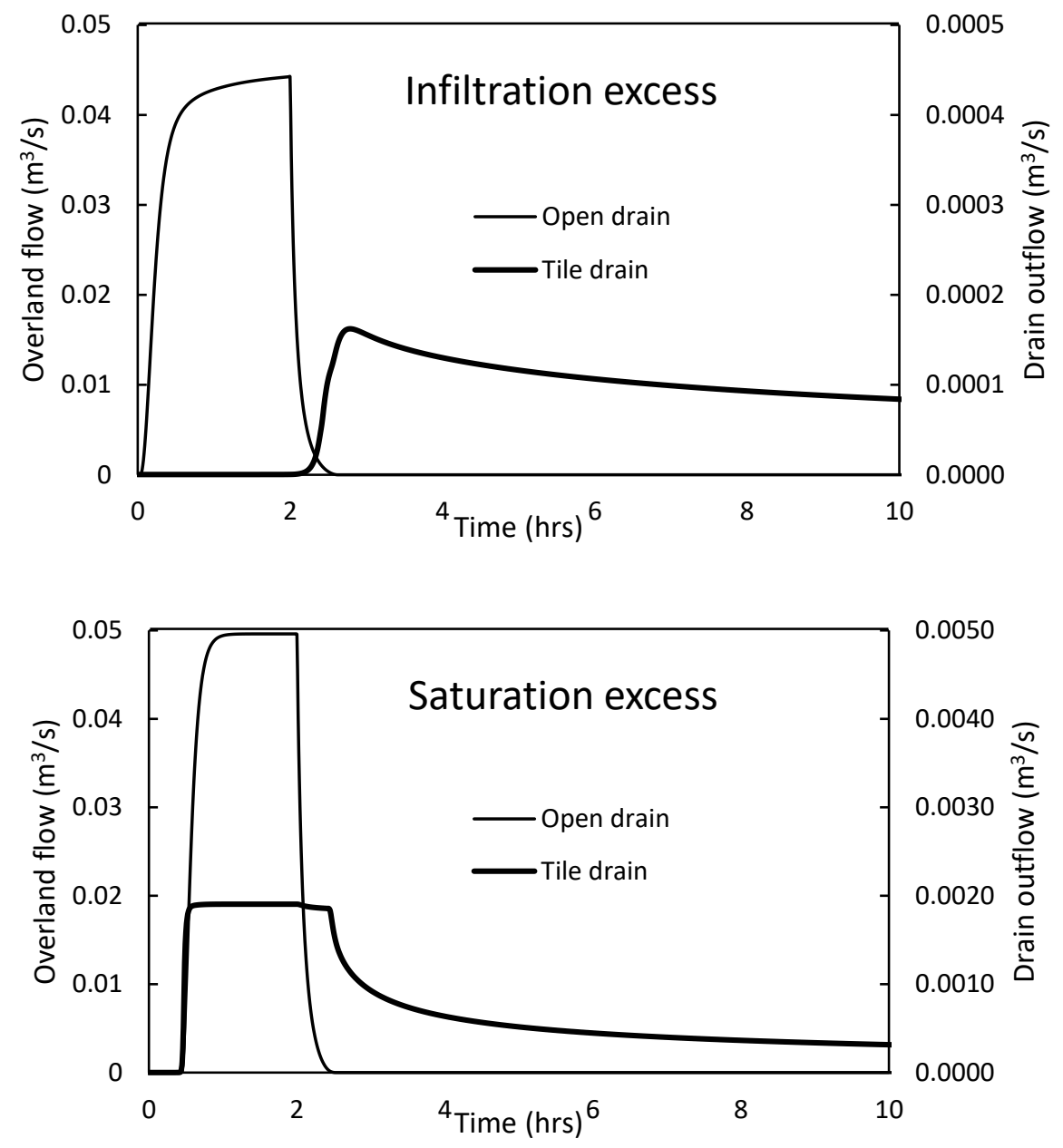

Fig 11. DrainFlow overland flow and tile drain hydrographs for saturated and infiltration excess scenarios for example 1

In the saturation excess scenario (infiltration rate $>$ rainfall rate), all rainfall entirely infiltrates and raises the groundwater table for the first 11 hours of simulation. At this point (ponding time), the soil profile becomes fully saturated and thereafter a portion of rainfall flows toward the open drain via overland flow. From the ponding time the hydrograph has a rapid jump 
to $0.049 \mathrm{~m}^{3} / \mathrm{s}$ in less than 2 hours and then remains stable for the rest of rainfall period.

However, in the infiltration excess scenario (infiltration rate $<$ rainfall rate) just a portion of rainfall infiltrates to the soil and the excess moves by overland flow to the open drain. This creates a hydrograph jump to $0.044 \mathrm{~m}^{3} / \mathrm{s}$ just after rainfall initiation and the outflow during the simulation time never reaches a steady state condition.

The tile drain hydrograph in the saturation excess scenario starts rising and reaches its peak almost at the same time as the overland flow, at around 11 hours. The tile drain hydrograph remains stable at about 0.002 $\mathrm{m}^{3} / \mathrm{s}$ to the end of the rainfall period. On the other hand, in the infiltration excess scenario, there is a 2.1 day delay between the beginning of the rainfall and the hydrograph peak in the tile drain. Similar to the open drain hydrograph, the tile drain hydrograph never reaches a steady state condition.

\subsubsection{Effect of $\mathbf{n}$ and Sx on tile drain hydrograph}

Compared to traditional drainage models, the DrainFlow code has the advantage of calculating the land surface recharge as a part of the model solution. Therefore, any change in the ground surface parameters (such as slopes, land use, evaporation and Manning roughness coefficient) has a direct effect on the land surface recharge. This then influences subsurface flow and tile drain outflows.

To illustrate these advantages, the saturation excess scenario model was run for a range of ground surface slopes and Manning roughness coefficients: $S_{x}=1 \mathrm{x}^{-4}, 1 \mathrm{x}^{-5}$ and $1 \mathrm{x}^{-6}$ and $n_{x}=n_{y}=0.1,0.06$ and 0.02 . The simulated tile drain hydrographs for each model run are shown in Fig 12. 

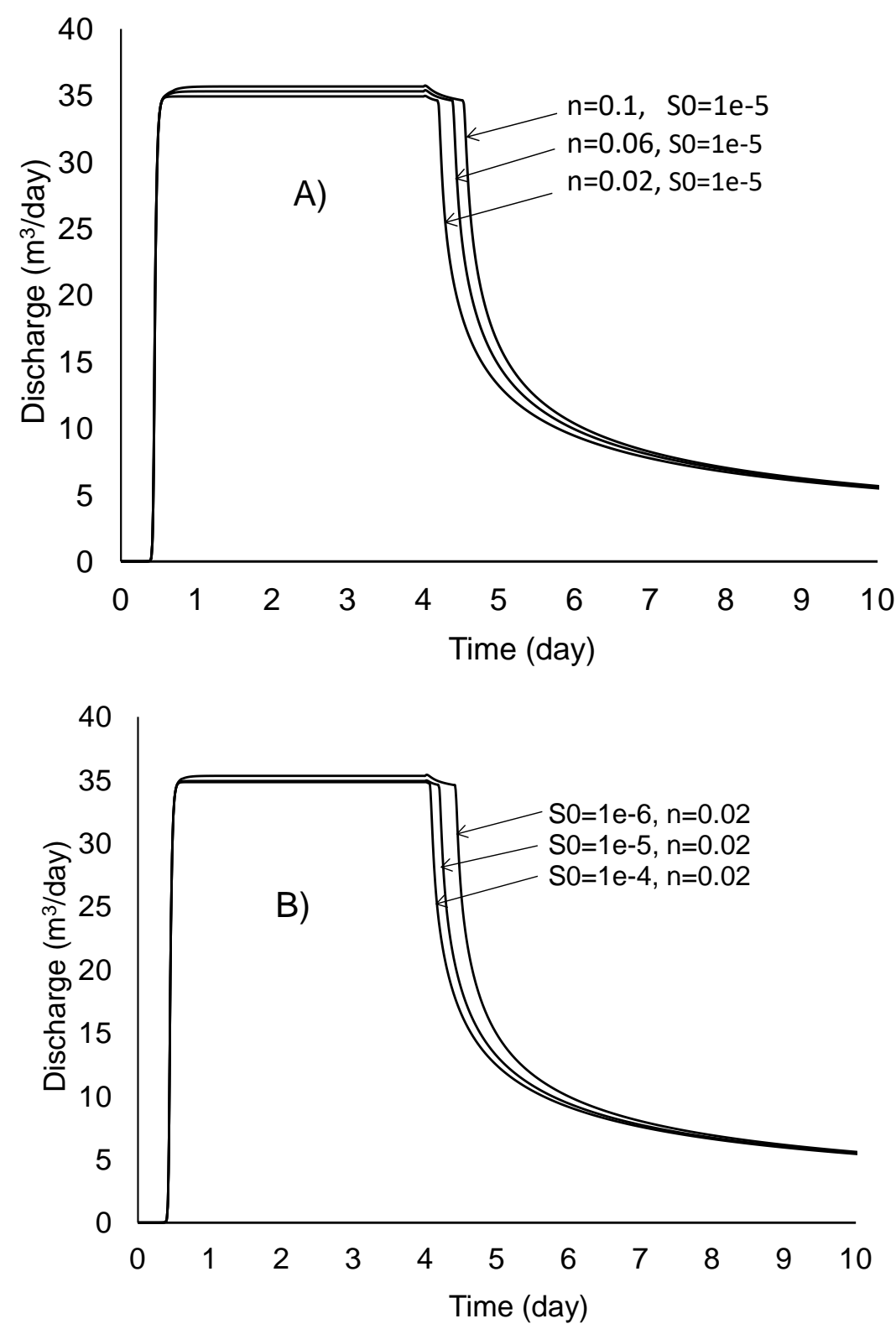

Fig 12. Tile drain hydrographs arising from (A). different ground surface Manning roughness coefficients and (B). ground surface slopes

The tile drain hydrographs show increasing the Manning roughness coefficient coupled with decreasing the ground surface slope would increase the total volume of water drained by the tile drain. Increasing Manning roughness coefficient from 0.02 to 0.06 and $0.1 \mathrm{~m}^{1 / 3} / \mathrm{s}$ resulted in $2.6 \%$ and $5.6 \%$ increases in the cumulative tile drain outflow respectively. However, reducing the ground surface slope from 0.0001 to 0.001 and $0.01 \%$, respectively, resulted in $3.8 \%$ and $5.5 \%$ increments in cumulative tile drain outflow. 


\section{Example 2 (Upscaling):}

For the second hypothetical tile drainage example the area of modelling is 10 times enlarged compared to Example 1. Also, the number of tile drains increase from one tile drain in first example to 10, 20, 40 and 80 tile drains. Moreover, another open drain module is added to collect the tile drain outflows as a main drain. However, the soil types, rainfall rate, evapotranspiration rate, tile drain types, and tile drains depth remains as for Example 1. Fig 13 shows a conceptual model for the case of 10 tile drains, together with utilised parameters.

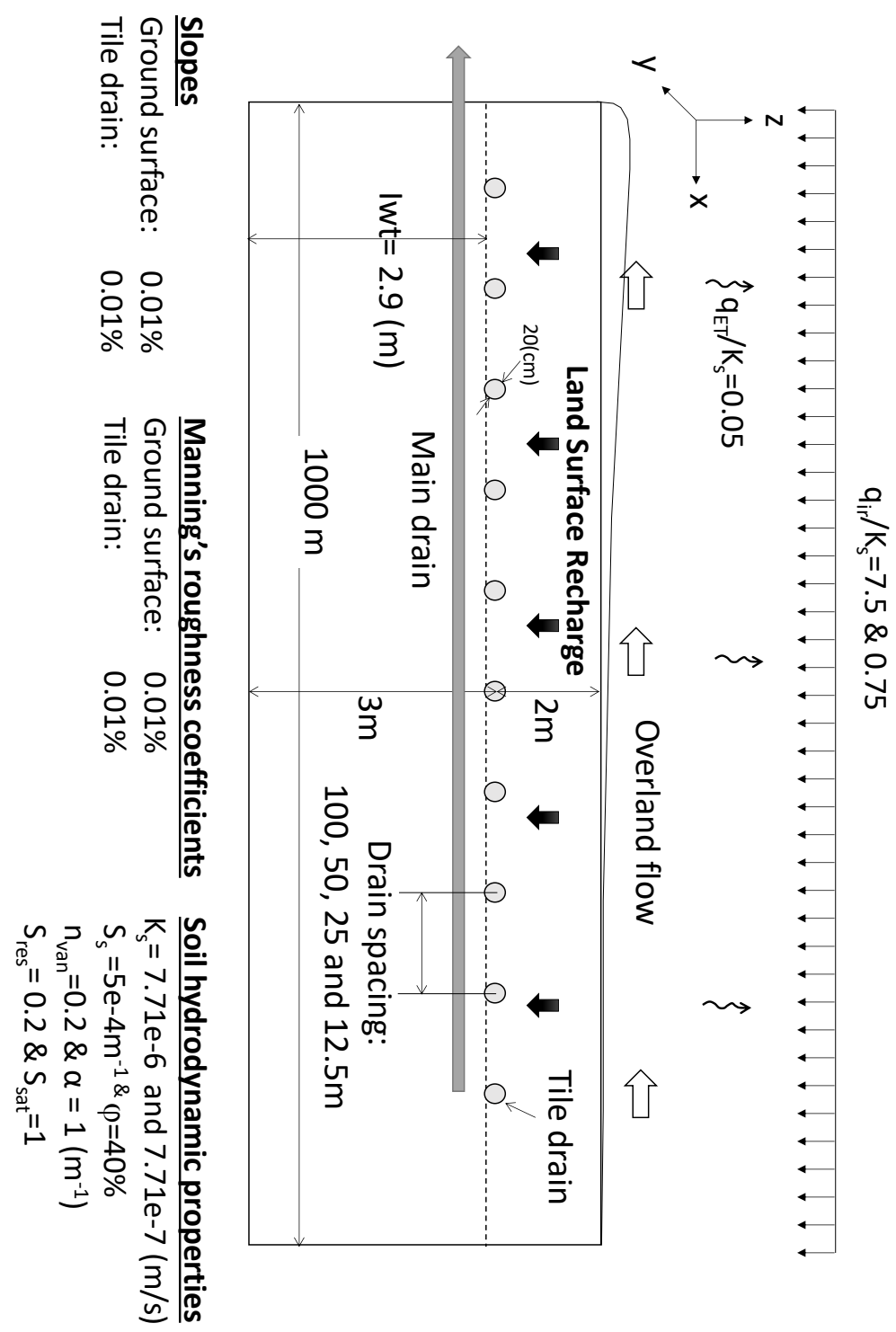

Fig 13. Example 2: conceptual model of overland-flow, subsurface flow, tile drains, main drain, and utilised parameters 
It would be expected to take much longer to solve for Example 2 than Example 1, due to more finite elements cells (particularly in the subsurface flow domain), and more tile drain modules. However, making some simplification assumptions were made that significantly facilitates the simulation process.

The first simplification involves reducing the subsurface and overland flow dimensions. The surface and subsurface flow in the $y$ direction, which is parallel to the tile drains direction, is assumed to be negligible. Therefore, the dimensions of overland flow module drops from 2 to 1 dimension. Similarly, the subsurface model dimension is dropped from 3 to 2 dimensions. This greatly reduces the number of utilised finite element cells in the model. For instance, in the 80 tile drains case the total number of finite element cells is reduced from 149,380 to 4,780 elements.

The second simplification assumption was to decrease the numbers of tile drain modules in the model by applying one tile drain module for the similar neighbour tile drains. This simplification could be made based on the similarities of parameters of the neighbour tile drains such as tile drain slopes, Manning roughness coefficients, and soil types.

These simplifications significantly decrease the computational solving time. For example, in the model consisting 80 tile drains, the computational solving time decreased from more than 10 days to less than 10 minutes by a standard desktop computer. \{good but what is your contribution? Are you saying that your model is good because unlike other models you can easily reduce dimensions which in turn enables in some cases much improved calculation speeds compared to other models\}

\subsubsection{10 tile drains}

The model of Example 2 containing 10 tile drains runs for a simulation period of 2 days rainfall followed by 8 days evapotranspiration for the saturated and infiltration excess runoff scenarios. DrainFlow-derived main drain and overland flow hydrographs at the outlets by DrainFlow are shown in Fig 14. 

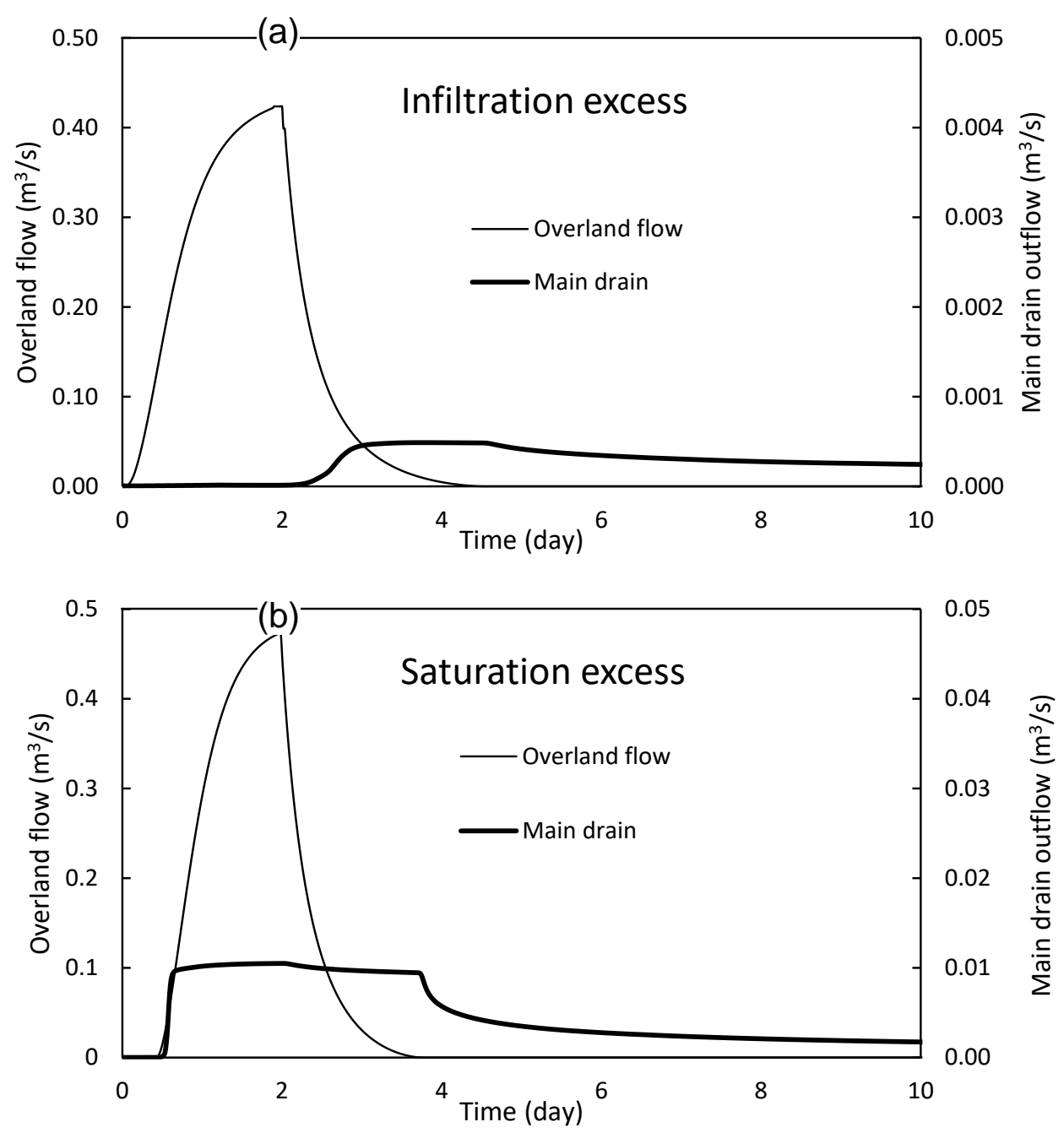

Fig 14. Overland flow and main-drain hydrographs: (a) saturated and (b) infiltration excess scenarios for the 10 tile drains domain

In the infiltration excess runoff scenario, the overland flow and the maindrain hydrograph respond to the rain event approximately in the same time with about a half day delay from the beginning of the rainfall. However, in the saturation excess runoff scenario, the overland flow hydrograph shows a very fast response to the rainfall in less than one hour. However, there is about 2 days delay between the beginning of rain and flow in the main drain. A comparison between overland flow hydrographs in Fig 14.a and 14.b indicates that the lower soil hydraulic conductivity in the infiltration excess scenario causes a higher percentage of rainfall drained by the surface drainage system in infiltration excess scenario than in the saturation excess scenario. 


\subsubsection{20, 40 and 80 tile drains}

DrainFlow was evaluated for 20,40 and 80 tile drains. That is, for 50,25 and $12.5 \mathrm{~m}$ tile drain spacing. The models were run to generate an infiltration excess runoff condition, so hydraulic conductivity was set to be smaller than the rainfall rate. Fig 15 shows the main drain and overland flow hydrographs for 10, 20, 40 and 80 tile drains, as computed DrainFlow.
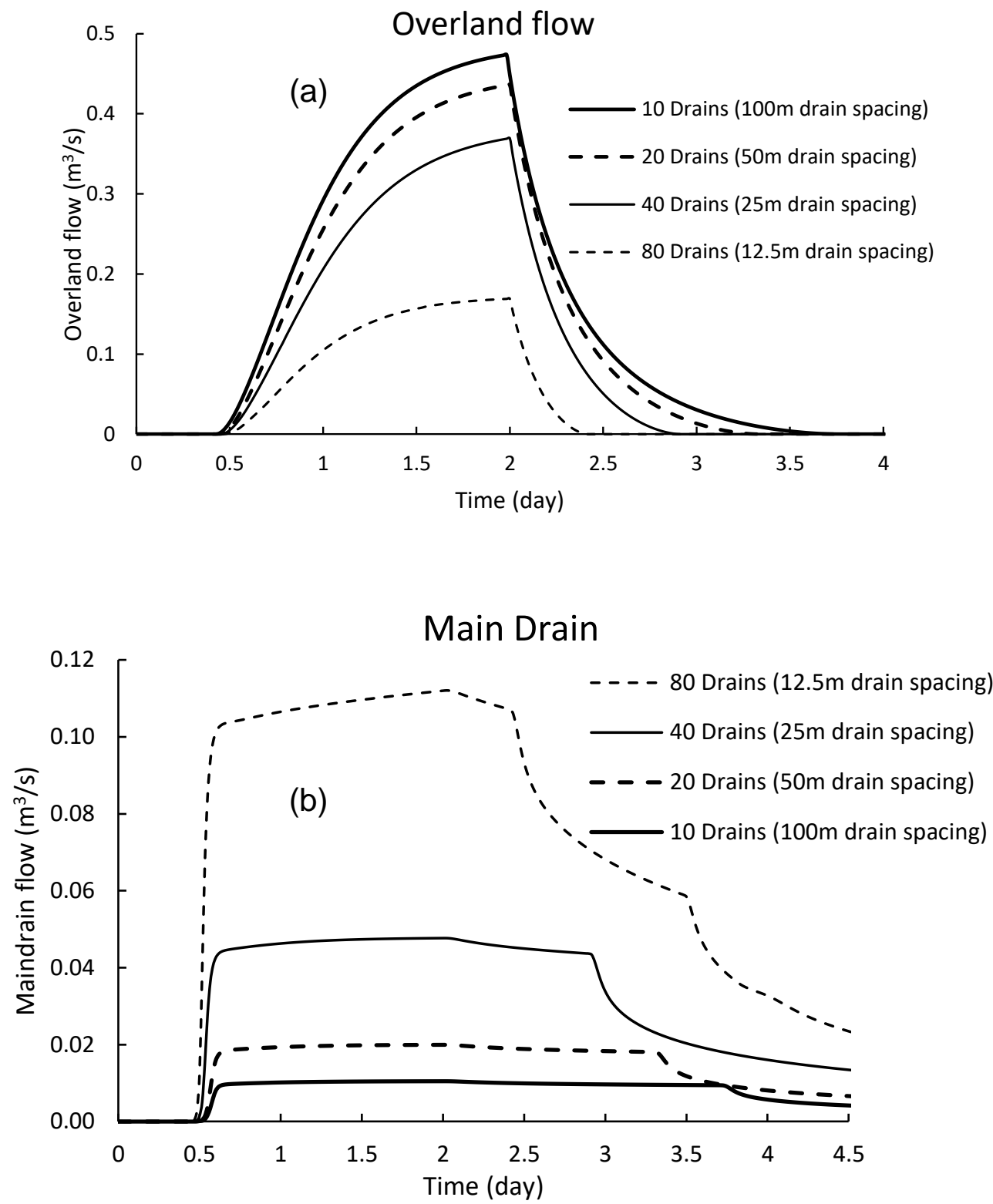

Fig 15. Comparisons between (a) overland flow and (b) tile drain hydrographs for infiltration excess runoff condition

Comparing the overland flow and the main drain hydrographs shows that increasing the number of tile drains could reduce runoff discharge but amplifies the main drain outflow. 
Fig 15 shows that when the tile drain spacing is $100,50,25$ and $12.5 \mathrm{~m}$ then the peak runoff discharges are $0.47,0.41,0.36$ and $0.15 \mathrm{~m}^{3} / \mathrm{s}$ and the corresponding maximum main drain outflows are $0.121,0.42,0.021$ and $0.009 \mathrm{~m}^{3} / \mathrm{s}$ respectively. Furthermore, the water balance shows around $12 \%$ of the total rainfall volume is drained by tile drains when the tile drain spacing is $100 \mathrm{~m}$, but this percentage increases to about $30 \%$ when tile drain spacing is $12.5 \mathrm{~m}$. Therefore it could be concluded that decreasing the tile drain spacing has effective impact on dropping the peak and cumulative runoff and increases the peak and total water drained water by the main drain.

\section{Conclusion}

DrainFlow is a fully distributed integrated surface and subsurface flow model, designed for drainage studies. Development, tests and applications of DrainFlow have been discussed. In contrast to the pervious drainage models, DrainFlow has the advantage of calculating land surface recharge directly from the partial differential form of the Richards equation rather than implementing empirical methods.

To develop the model, a range of modules are separately formulated. Each module is then connected to the related modules. Consequently, all modules work together simultaneously by using outcomes of the other modules to yield the final result. A new technique is included in DrainFlow as a guard against the nonlinearity issue, which often occurs in coupled surface -subsurface flow models because of switching between dry and wet boundary conditions. This method provides for smooth switching between dry and wet boundary conditions.

To compare the DrainFlow code with the other coupled surface and subsurface flow models, some comparisons are made for five well-known integrated surface and subsurface benchmarks. As a result of these comparisons, it is concluded that the DrainFlow code is in reasonably good agreement with the other coupled surface and subsurface flow codes. 
In addition, two new hypothetical tile drainage examples were introduced and the DrainFlow code was run for these examples. The first example is designed to challenge the DrainFlow code in high-resolution and smallscale tile drainage studies. It was shown that DrainFlow code can compute effects of ground surface Manning roughness coefficients and slopes on the tile drain hydrographs, which was not predictable by traditional tile drainage models.

The second example was designed to challenge DrainFlow with model upscaling issue. As a result of two additional simplification assumptions the computational solving time declined dramatically from 10 days to less than 10 minutes in a model comprising 80 tile drains.

Finally, on the basis of various tests and applications it is concluded that in addition to comprehensiveness, DrainFlow is quite flexible. Based on required conceptual model complexity, scale and data availability, DrainFlow can be easily modified dimensionally or methodologically to a less or more complex model.

Reference

[1] Skaggs RW. DRAINMOD: Reference Report - Methods for Design and Evaluation of Drainage-Water Management Systems for Soils with High Water Tables. USDA-SCS. Fort Worth, TX., 1980.

[2] Hooghoudt SB. Bijdragen tot de kennis van eenige natuurkundige grootheden van den grond. No. 7. Algemeene beschouwing van het probleem van de detailontwatering en de infiltratie door middel van parallel loopende drains, greppels, slooten en kanalen. Verslagen van Landbouwkundige Onderzoekingen. 46 (1940) 515-707.

[3] Moody W. Nonlinear differential equation of drain spacing. J Irrig Drainage Eng-ASCE. 92 (1966) 1-10.

[4] Sakkas JG, VZ Antonopoulos. Simple equations for hooghoudt equivalent depth. ASCE J Irrig Drainage Divi. 107 (1981) 411-4. 
[5] Mishra GC, V Singh. A new drain spacing formula. Hydrological Sciences Journal. 52 (2007) 338 - 51.

[6] Mishra GC, V Singh. Reply to discussion of "A new drain spacing formula". Hydrological Sciences Journal. 53 (2008) 935-7.

[7] Çimen M. Discussion of "A new drain spacing formula". Hydrological Sciences Journal. 53 (2008) 933-4.

[8] Kirkham D. Seepage of steady rainfall through soil into drains. Trans Am Geophys Union. 36 (1958) 892-908.

[9] Van der Molen WH, J Wesseling. A solution in closed form and a series solution to replace the tables for the thickness of the equivalent layer in Hooghoudt's drain spacing formula. Agric Water Manage. 19 (1991) 1-16.

[10] Dagan G. Spacings of drains by an approximate method. J Irrig Drainage Eng-ASCE. 91 (1964) 41-6.

[11] Hammad HY. Depth and spacing of tile drain systems. Proceedings of ASCE, Journal of the Irrigation and Drain div. 83 (1962) 15-33.

[12] Ernst LF. Grondwaterstromingen in de verzadigde zone en hun berekening bij aanwezigheid van horizontale evenwijdige open leidingen. Centrum voor Landbouwpublikaties en Landbouwdocumetatie, 1962. [13] Youngs EG. The effect of the depth of an impermeable barrier on water-table heights in drained homogeneous soils. Journal of Hydrology. 24 (1975) 283-90.

[14] Youngs EG. Horizontal seepage through unconfined aquifers with hydraulic conductivity varying with depth. Journal of Hydrology. 3 (1965) 283-96.

[15] List EJ. The steady flow of precipitation to an infinite series of tile drains above an impervious layer. Journal of Geophysical Research. 69 (1964) 3371-81, doi: 10.1029/JZ069i016p03371.

[16] Childs EC. An introduction to the physical basis of soil water phenomena. J. Wiley, 1969. 
[17] Collis-George N, EG Youngs. Some factors determining water-table heights in drained homogeneous soils. Journal of Soil Science. 9 (1958) 332-8, doi: 10.1111/j.1365-2389.1958.tb01924.x.

[18] Miles JC, K Kitmitto. New drain flow formula. Journal of Irrigation and Drainage Engineering. 115 (1989) 215-30.

[19] Barua, Tiwari. Theories of ditch drainage in layered anisotropic soil. Journal of Irrigation and Drainage Engineering. 122 (1996) 321-30, doi: doi:10.1061/(ASCE)0733-9437(1996)122:6(321).

[20] Barua, Tiwari. Ditch drainage theories for homogeneous anisotropic soil. Journal of Irrigation and Drainage Engineering. 122 (1996) 276-85, doi: doi:10.1061/(ASCE)0733-9437(1996)122:5(276).

[21] Lovell CJ, EG Youngs. A comparison of steady-state land-drainage equations. Agricultural Water Management. 9 (1984) 1-21, doi:

http://dx.doi.org/10.1016/0378-3774(84)90015-5.

[22] Kirkham D. Steady-state theories for land drainage. Journal of Irrigation and Drainage Engineering. 92 (1966) 19-39.

[23] Youngs E. Effect of the Capillary Fringe on Steady-State Water Tables in Drained Lands. Journal of Irrigation and Drainage Engineering. 138 (2012) 809-14, doi: doi:10.1061/(ASCE)IR.1943-4774.0000467.

[24] Youngs E. Effect of the Capillary Fringe on Steady-State Water Tables in Drained Lands. II: Effect of an Underlying Impermeable Bed. Journal of Irrigation and Drainage Engineering. 139 (2013) 309-12, doi: doi:10.1061/(ASCE)IR.1943-4774.0000531.

[25] Gureghian AB, EG Youngs. The calculation of steady-state watertable heights in drained soils by means of the finite-element method. Journal of Hydrology. 27 (1975) 15-32, doi: http://dx.doi.org/10.1016/00221694(75)90096-7.

[26] Zaradny H, RA Feddes. Calculation of non-steady flow towards a drain in saturated-unsaturated soil by finite elements. Agric Water Manage. 2 (1979) 37-53, doi: http://dx.doi.org/10.1016/0378-3774(79)90012-X. 
[27] Smedema LK, A Poelman, W De Haan. Use of the Hooghoudt formula for drain spacing calculations in homogeneous-anisotropic soils. Agric Water Manage. 10 (1985) 283-91, doi: http://dx.doi.org/10.1016/03783774(85)90017-4.

[28] Khan S, KR Rushton. Reappraisal of flow to tile drains I. Steady state response. Journal of Hydrology. 183 (1996) 351-66, doi:

http://dx.doi.org/10.1016/0022-1694(95)02947-8.

[29] Khan S, KR Rushton. Reappraisal of flow to tile drains II. Time-variant response. Journal of Hydrology. 183 (1996) 367-82, doi:

http://dx.doi.org/10.1016/0022-1694(95)02948-6.

[30] Khan S, KR Rushton. Reappraisal of flow to tile drains III. Drains with limited flow capacity. Journal of Hydrology. 183 (1996) 383-95, doi: http://dx.doi.org/10.1016/0022-1694(95)02949-4.

[31] Zaradny H. Application of confined aquifer theory for verification of solutions of water flow towards a drain in saturated-unsaturated soil. Agricultural Water Management. 47 (2001) 155-78, doi:

http://dx.doi.org/10.1016/S0378-3774(00)00100-1.

[32] Zavala M, C Fuentes, H Saucedo. Non-linear radiation in the Boussinesq equation of the agricultural drainage. Journal of Hydrology. 332 (2007) 374-80.

[33] Castanheira P, F Santos. A simple numerical analyses software for predicting water table height in subsurface drainage. Irrigation and Drainage Systems. 23 (2009) 153-62, doi: 10.1007/s10795-009-9079-5.

[34] Pandey R, A Bhattacharya, O Singh, S Gupta. Drawdown Solutions with Variable Drainable Porosity. Journal of Irrigation and Drainage Engineering. 118 (1992) 382-96, doi: doi:10.1061/(ASCE)07339437(1992)118:3(382).

[35] Chavez C, C Fuentes, M Zavala, F Brambila. Numerical solution of the Boussinesq equation: Application to the agricultural drainage. Afr $\mathrm{J}$ Agric Res. 6 (2011) 4210-22. 
[36] Chavez C, C Fuentes, M Zavala, F Zatarain. Finite difference solution of the Boussinesq equation with variable drainable porosity and fractal radiation boundary condition. Agrociencia. 45 (2011) 911-27.

[37] Jiang X-W, L Wan, T-CJ Yeh, X-S Wang, L Xu. Steady-state discharge into tunnels in formations with random variability and depthdecaying trend of hydraulic conductivity. Journal of Hydrology. 387 (2010) 320-7, doi: http://dx.doi.org/10.1016/.j.hydrol.2010.04.024.

[38] Shokri A, W Bardsley. Enhancement of the Hooghoudt Drain-Spacing Equation. Journal of Irrigation and Drainage Engineering. 141 (2014) 04014070, doi: 10.1061/(asce)ir.1943-4774.0000835.

[39] Skaggs RW. A water management model for artificially drained soils. North Carolina Agricultural Research Service, 1980.

[40] Tiemeyer B, R Moussa, B Lennartz, M Voltz. MHYDAS-DRAIN: A spatially distributed model for small, artificially drained lowland catchments. Ecological Modelling. 209 (2007) 2-20, doi: http://dx.doi.org/10.1016/i.ecolmodel.2007.07.003.

[41] Schoups G, JW Hopmans, CA Young, JA Vrugt, WW Wallender, KK Tanji, et al. Sustainability of irrigated agriculture in the San Joaquin Valley, California. Proceedings of the National Academy of Sciences. 102 (2005) 15352-6, doi: 10.1073/pnas.0507723102.

[42] Zerihun D, A Furman, AW Warrick, CA Sanchez. Coupled surfacesubsurface flow model for improved basin irrigation management. Journal of Irrigation and Drainage Engineering. 131 (2005) 111-28.

[43] Zerihun D, A Furman, AW Warrick, CA Sanchez. Coupled surfacesubsurface solute transport model for irrigation borders and basins. I. Model development. Journal of Irrigation and Drainage Engineering. 131 (2005) 396-406.

[44] Rozemeijer JC, Y van der Velde, RG McLaren, FC van Geer, HP Broers, MFP Bierkens. Integrated modeling of groundwater-surface water interactions in a tile-drained agricultural field: The importance of directly 
measured flow route contributions. Water Resources Research. 46 (2010) n/a-n/a, doi: 10.1029/2010wr009155.

[45] Shokri A. Developing a new numerical surface/subsurface model for irrigation and drainage system design. Symposium $\mathrm{H} 01$ on Conceptual and Modelling Studies of Integrated Groundwater, Surface Water, and Ecological Systems, Held During the 25th General Assembly of the International Union of Geodesy and Geophysics, IUGG 2011, June 28, 2011 - July 7, 2011. IAHS Press, Melbourne, VIC, Australia, 2011. pp. 759.

[46] Banti M, T Zissis, E Anastasiadou-Partheniou. Furrow irrigation advance simulation using a surface-subsurface interaction model. Journal of Irrigation and Drainage Engineering. 137 (2011) 304-14.

[47] Dong Q, D Xu, S Zhang, M Bai, Y Li. A hybrid coupled model of surface and subsurface flow for surface irrigation. Journal of Hydrology. 500 (2013) 62-74, doi: http://dx.doi.org/10.1016/i.jhydrol.2013.07.018.

[48] Morrison AK. Limitations on the study of tile drainage using a distributed parameter hydrologic model and stable isotopes. lowa State University, 2014.

[49] Weill S, A Mazzia, M Putti, C Paniconi. Coupling water flow and solute transport into a physically-based surface-subsurface hydrological model. Advances in Water Resources. 34 (2011) 128-36.

[50] Sudicky E, J Jones, Y-J Park, A Brookfield, D Colautti. Simulating complex flow and transport dynamics in an integrated surface-subsurface modeling framework. Geosci J. 12 (2008) 107-22, doi: 10.1007/s12303008-0013-x.

[51] Li S, CJ Duffy. Fully coupled approach to modeling shallow water flow, sediment transport, and bed evolution in rivers. Water Resources Research. 47 (2011) n/a-n/a, doi: 10.1029/2010wr009751.

[52] Ran Q, CS Heppner, JE VanderKwaak, K Loague. Further testing of the integrated hydrology model (InHM): multiple-species sediment 
transport. Hydrological Processes. 21 (2007) 1522-31, doi:

10.1002/hyp.6642.

[53] Liang D, RA Falconer, B Lin. Coupling surface and subsurface flows in a depth averaged flood wave model. Journal of Hydrology. 337 (2007) 147-58.

[54] Liggett JE, AD Werner, BD Smerdon, D Partington, CT Simmons. Fully integrated modeling of surface-subsurface solute transport and the effect of dispersion in tracer hydrograph separation. Water Resources Research. 50 (2014) 7750-65, doi: 10.1002/2013wr015040.

[55] Partington D, P Brunner, S Frei, CT Simmons, AD Werner, R Therrien, et al. Interpreting streamflow generation mechanisms from integrated surface-subsurface flow models of a riparian wetland and catchment. Water Resources Research. 49 (2013) 5501-19, doi: 10.1002/wrcr.20405.

[56] Partington D, P Brunner, CT Simmons, R Therrien, AD Werner, GC Dandy, et al. A hydraulic mixing-cell method to quantify the groundwater component of streamflow within spatially distributed fully integrated surface water-groundwater flow models. Environmental Modelling \& Software. 26 (2011) 886-98.

[57] Meyerhoff S, R Maxwell. Quantifying the effects of subsurface heterogeneity on hillslope runoff using a stochastic approach. Hydrogeol J. 19 (2011) 1515-30, doi: 10.1007/s10040-011-0753-y.

[58] Kollet SJ, RM Maxwell. Demonstrating fractal scaling of baseflow residence time distributions using a fully-coupled groundwater and land surface model. Geophysical Research Letters. 35 (2008) n/a-n/a, doi: 10.1029/2008gl033215.

[59] Bayani Cardenas M. The effect of river bend morphology on flow and timescales of surface water-groundwater exchange across pointbars. Journal of Hydrology. 362 (2008) 134-41, doi: http://dx.doi.org/10.1016/j.jhydrol.2008.08.018. 
[60] Guay C, M Nastev, C Paniconi, M Sulis. Comparison of two modeling approaches for groundwater-surface water interactions. Hydrological Processes. 27 (2013) 2258-70, doi: 10.1002/hyp.9323.

[61] Smerdon BD, CA Mendoza, KJ Devito. Influence of subhumid climate and water table depth on groundwater recharge in shallow outwash aquifers. Water Resources Research. 44 (2008) n/a-n/a, doi: 10.1029/2007wr005950.

[62] Lemieux JM, EA Sudicky, WR Peltier, L Tarasov. Dynamics of groundwater recharge and seepage over the Canadian landscape during the Wisconsinian glaciation. Journal of Geophysical Research: Earth Surface. 113 (2008) n/a-n/a, doi: 10.1029/2007jf000838.

[63] Delfs J-O, W Wang, T Kalbacher, A Singh, O Kolditz. A coupled surface/subsurface flow model accounting for air entrapment and air pressure counterflow. Environ Earth Sci. 69 (2013) 395-414, doi: 10.1007/s12665-013-2420-1.

[64] Sulis M, C Paniconi, M Camporese. Impact of grid resolution on the integrated and distributed response of a coupled surface-subsurface hydrological model for the des Anglais catchment, Quebec. Hydrological Processes. 25 (2011) 1853-65, doi: 10.1002/hyp.7941.

[65] Gauthier MJ, M Camporese, C Rivard, C Paniconi, M Larocque. A modeling study of heterogeneity and surface water-groundwater interactions in the Thomas Brook catchment, Annapolis Valley (Nova Scotia, Canada). Hydrol Earth Syst Sci. 13 (2009) 1583-96, doi: 10.5194/hess-13-1583-2009.

[66] Camporese M, C Paniconi, M Putti, P Salandin. Ensemble Kalman filter data assimilation for a process-based catchment scale model of surface and subsurface flow. Water Resources Research. 45 (2009) n/an/a, doi: 10.1029/2008wr007031.

[67] Mirus BB, K Loague, JE VanderKwaak, SK Kampf, SJ Burges. A hypothetical reality of Tarrawarra-like hydrologic response. Hydrological Processes. 23 (2009) 1093-103, doi: 10.1002/hyp.7241. 
[68] Maxwell RM, SJ Kollet. Quantifying the effects of three-dimensional subsurface heterogeneity on Hortonian runoff processes using a coupled numerical, stochastic approach. Advances in Water Resources. 31 (2008) 807-17, doi: http://dx.doi.org/10.1016/j.advwatres.2008.01.020.

[69] Li Q, AJA Unger, EA Sudicky, D Kassenaar, EJ Wexler, S Shikaze. Simulating the multi-seasonal response of a large-scale watershed with a 3D physically-based hydrologic model. Journal of Hydrology. 357 (2008) 317-36, doi: http://dx.doi.org/10.1016/i.jhydrol.2008.05.024.

[70] Jones JP, EA Sudicky, RG McLaren. Application of a fully-integrated surface-subsurface flow model at the watershed-scale: A case study. Water Resources Research. 44 (2008) n/a-n/a, doi: 10.1029/2006wr005603.

[71] Qu Y, CJ Duffy. A semidiscrete finite volume formulation for multiprocess watershed simulation. Water Resources Research. 43 (2007) n/a-n/a, doi: 10.1029/2006wr005752.

[72] Heppner CS, K Loague, JE VanderKwaak. Long-term InHM simulations of hydrologic response and sediment transport for the R-5 catchment. Earth Surface Processes and Landforms. 32 (2007) 1273-92, doi: 10.1002/esp.1474.

[73] Ebel BA, K Loague, JE Vanderkwaak, WE Dietrich, DR Montgomery, $R$ Torres, et al. Near-surface hydrologic response for a steep, unchanneled catchment near Coos Bay, Oregon: 2. Physics-based simulations. American Journal of Science. 307 (2007) 709-48, doi: 10.2475/04.2007.03.

[74] Kollet S, R Maxwell. Capturing the influence of groundwater dynamics on land surface processes using an integrated, distributed watershed model. Water Resour Res. 44 (2008).

[75] Kollet SJ, RM Maxwell. Integrated surface-groundwater flow modeling: A free-surface overland flow boundary condition in a parallel groundwater flow model. Advances in Water Resources. 29 (2006) 945-58. 
[76] Maxwell RM, NL Miller. Development of a Coupled Land Surface and Groundwater Model. Journal of Hydrometeorology. 6 (2005) 233-47, doi: doi:10.1175/JHM422.1.

[77] Shen C, MS Phanikumar. A process-based, distributed hydrologic model based on a large-scale method for surface-subsurface coupling. Advances in Water Resources. 33 (2010) 1524-41.

[78] M. Camporese CP, M. Putti, and S. Orlandini. Surface-subsurface flow modeling with path-based runoff routing, boundary condition-based coupling, and assimilation of multisource observation data. Water Resources Research. 46 (2010) W02512, doi: 10.1029/2008WR007536.

[79] Brunner P, CT Simmons. HydroGeoSphere: A Fully Integrated, Physically Based Hydrological Model. Ground Water. 50 (2012) 170-6, doi: 10.1111/j.1745-6584.2011.00882.x.

[80] Aquanty Inc. HydroGeoSphere User Manual. HGS Waterloo, Ontario, Canada, 2013.

[81] Kumar M, CJ Duffy, KM Salvage. A Second-Order Accurate, Finite Volume-Based, Integrated Hydrologic Modeling (FIHM) Framework for Simulation of Surface and Subsurface Flow. Vadose Zone Journal. 8 (2009) 873-90, doi: 10.2136/vzj2009.0014.

[82] Kim J, VY Ivanov, ND Katopodes. Modeling erosion and sedimentation coupled with hydrological and overland flow processes at the watershed scale. Water Resources Research. 49 (2013) 5134-54, doi: 10.1002/wrcr.20373.

[83] Ivanov VY, S Fatichi, GD Jenerette, JF Espeleta, PA Troch, TE Huxman. Hysteresis of soil moisture spatial heterogeneity and the "homogenizing" effect of vegetation. Water Resources Research. 46 (2010) n/a-n/a, doi: 10.1029/2009wr008611.

[84] Ivanov VY, RL Bras, ER Vivoni. Vegetation-hydrology dynamics in complex terrain of semiarid areas: 1 . A mechanistic approach to modeling 
dynamic feedbacks. Water Resources Research. 44 (2008) n/a-n/a, doi: 10.1029/2006wr005588.

[85] Delfs JO, E Kalbus, CH Park, O Kolditz. A physically based model concept for transport modelling in coupled hydrosystems. Grundwasser. 14 (2009) 219-35, doi: 10.1007/s00767-009-0114-0.

[86] Delfs JO, CH Park, O Kolditz. A sensitivity analysis of Hortonian flow. Advances in Water Resources. 32 (2009) 1386-95, doi:

http://dx.doi.org/10.1016/i.advwatres.2009.06.005.

[87] Delfs J-O, F Blumensaat, W Wang, P Krebs, O Kolditz. Coupling hydrogeological with surface runoff model in a Poltva case study in Western Ukraine. Environ Earth Sci. 65 (2012) 1439-57, doi: 10.1007/s12665-011-1285-4.

[88] Richards LA. Capillary conduction of liquids through porous mediums. Physics. 1 (1931) 31833.

[89] Green WH, GA Ampt. Studies on soil physics, 1, The flow of air and water through soils. J Agric Sci. 4 (1911).

[90] Weiyan T. Shallow Water Hydrodynamics Mathematical Theory and Numerical Solution for a Two - dimensional System of Shallow Water Equations. Oceanography. (1992).

[91] Panday S, PS Huyakorn. A fully coupled physically-based spatiallydistributed model for evaluating surface/subsurface flow. Advances in Water Resources. 27 (2004) 361-82.

[92] Van Genuchten MT. Closed-form equation for predicting the hydraulic conductivity of unsaturated soils. Soil Sci Soc Am J. 44 (1980) 892-8.

[93] COMSOL. COMSOL Multiphysics User's Guide, May 2012.

[94] Maxwell RM, M Putti, S Meyerhoff, J-O Delfs, IM Ferguson, V Ivanov, et al. Surface-subsurface model intercomparison: A first set of benchmark results to diagnose integrated hydrology and feedbacks. Water Resources Research. 50 (2014) 1531-49, doi: 10.1002/2013wr013725. 